\title{
Stable nuclear transformation of Eudorina elegans
}

Kai Lerche and Armin Hallmann*

\begin{abstract}
Background: A fundamental step in evolution was the transition from unicellular to differentiated, multicellular organisms. Volvocine algae have been used for several decades as a model lineage to investigate the evolutionary aspects of multicellularity and cellular differentiation. There are two well-studied volvocine species, a unicellular alga (Chlamydomonas reinhardtii) and a multicellular alga with differentiated cell types (Volvox carteri). Species with intermediate characteristics also exist, which blur the boundaries between unicellularity and differentiated multicellularity. These species include the globular alga Eudorina elegans, which is composed of 16-32 cells. However, detailed molecular analyses of $E$. elegans require genetic manipulation. Unfortunately, genetic engineering has not yet been established for Eudorina, and only limited DNA and/or protein sequence information is available.

Results: Here, we describe the stable nuclear transformation of E. elegans by particle bombardment using both a chimeric selectable marker and reporter genes from different heterologous sources. Transgenic algae resistant to paromomycin were achieved using the aminoglycoside 3'-phosphotransferase VIII (aphVIII) gene of Streptomyces rimosus, an actinobacterium, under the control of an artificial promoter consisting of two $V$. carteri promoters in tandem. Transformants exhibited an increase in resistance to paromomycin by up to 333-fold. Co-transformation with non-selectable plasmids was achieved with a rate of $50-100 \%$. The luciferase (g/uc) gene from the marine copepod Gaussia princeps, which previously was engineered to match the codon usage of C. reinhardtii, was used as a reporter gene. The expression of gluc was mediated by promoters from C. reinhardtii and V. carteri. Heterologous heat shock promoters induced an increase in luciferase activity (up to 600-fold) at elevated temperatures. Long-term stability and both constitutive and inducible expression of the co-bombarded gluc gene was demonstrated by transcription analysis and bioluminescence assays.

Conclusions: Heterologous flanking sequences, including promoters, work in E. elegans and permit both constitutive and inducible expression of heterologous genes. Stable nuclear transformation of E. elegans is now routine. Thus, we show that genetic engineering of a species is possible even without the resources of endogenous genes and promoters.
\end{abstract}

Keywords: Co-transformation, Gaussia princeps luciferase gene, Genetic engineering, Green algae, Heterologous expression, Reporter genes, Selectable markers, Streptomyces rimosus aphVIII gene, Volvocaceae, Volvocine algae

\section{Background}

The evolution of multicellularity and the separation of germline cells from sterile somatic cells are certainly among the greatest innovations of eukaryotes. Remarkably, phylogenetic analysis suggests that the shift from unicellular to multicellular organisms with differentiated cells was not a unique progression in the evolution of life, but it was, in fact, a frequent event [1-4].

Particularly with regard to questions related to the evolution of multicellularity and of the germ-soma

\footnotetext{
* Correspondence: armin.hallmann@gmx.de

Department of Cellular and Developmental Biology of Plants, University of Bielefeld, Universitätsstr. 25, D-33615, Bielefeld, Germany
}

dichotomy, the volvocine green algae within the Volvocales (Chlorophyta) order are of special interest. The volvocine green algae form a closely related group of flagellated, photosynthetic, phototactic, facultatively sexual haploid eukaryotes which include unicellular, colonial and multicellular forms with differentiated cell types [5-7]. Several genera of the volvocine lineage can be arranged in a conceptual series according to increasing morphologic and developmental complexity (from Chlamydomonas through Gonium, Pandorina, Eudorina and Pleodorina to Volvox) [5-7]. In this series there are progressive increases in cell number, organismal polarity, volume of extracellular matrix per cell, size of adult organisms,
C Biomed Central 
and the tendency to produce sterile, terminally differentiated somatic cells [5-7]. The unicellular alga Chlamydomonas shows the simplest possible morphologic and developmental complexity in this conceptual series; the cell grows in size and cell division produces unicellular daughter cells. The colonial alga Gonium has the shape of a slightly convex plate, typically containing 8-16-cells; all cells grow and divide to produce new colonies. Pandorina forms a 16-celled ellipsoid colony; all its cells grow and divide. Eudorina is a 16-32 celled, globular alga; generally, all cells of Eudorina grow and divide, but in some instances the 2-4 most anterior cells fail to divide and act as somatic cells $[7,8]$. Pleodorina is a $32-128$ celled, globular alga, in which all anterior cells remain small and function as non-dividing somatic cells, while all posterior cells grow and divide. The multicellular, globular alga Volvox exhibits the most advanced morphologic and developmental complexity in the volvocine lineage; it consists of many hundreds to thousands of cells and almost all cells terminally differentiate as small, biflagellate somatic cells, while only a very few cells grow up to many times their initial size and then divide to produce new individuals.

The diversity of volvocine forms provides an ideal model system for addressing fundamental molecular issues related to the transition to differentiated multicellularity. So far, the most intensively studied members of the volvocine algae group with sequenced genomes and wellestablished molecular-genetic tools are Chlamydomonas reinhardtii $[9,10]$ and Volvox carteri [4-7]. Less research has been done into the molecular characteristics of volvocine genera with intermediate organizational complexity between unicellular forms and multicellular forms with fully differentiated somatic and germ cells; these genera include Gonium [7,11-17], Pandorina [7,18-23], Eudorina [7,8,24-36] and Pleodorina [7,13,37-43].

Detailed molecular analyses of volvocine genera with intermediate organizational complexity require genetic manipulation. Therefore, our goal was to establish the stable, nuclear transformation of E. elegans, a volvocine species with intermediate organizational complexity (Figure 1). Molecular-genetic tools do currently not exist for E. elegans and this species has not been genetically engineered previously. We intended to develop a biolistic transformation method because previous biolistic methods were successful in three volvocine species, $V$. carteri [44], G. pectorale [17], and C. reinhardtii [45]. It should be mentioned that transformation methods using glass beads [46] or electroporation [47] are inappropriate for Eudorina because they require cell-wall deficient target cells, which do not exist for this species. Moreover, only limited sequence information is available for Eudorina, with the exception of several short DNA fragments that have been used as phylogenetic marker sequences [40,48-58].

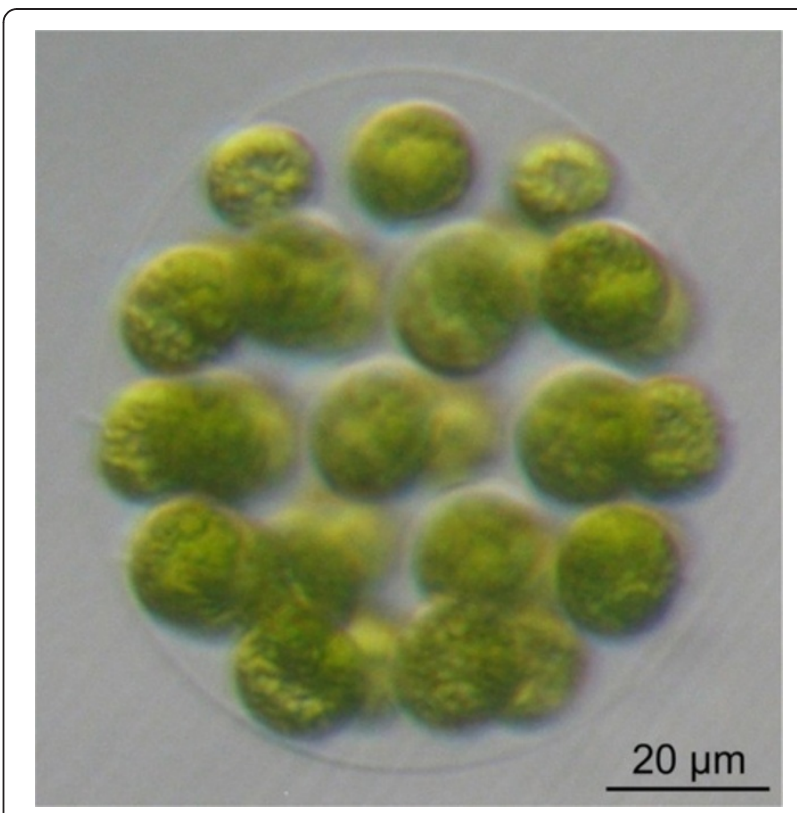

Figure 1 The wild-type phenotype of E. elegans. A vegetatively grown spheroid of E. elegans with $\sim 32$ biflagellate cells at the surface of the organism is shown. Each round-shaped cell contains a single large, cup-shaped chloroplast. Most of the spheroid volume consists of a complex but transparent glycoprotein-rich extracellular matrix that holds all of the cells in place.

An important prerequisite for transformation is a selectable marker gene for the identification of putative transformants. Under the given conditions of Eudorina, a heterologous, dominant marker was preferred because it allows for the transformation of wild-type strains, i.e., auxotrophic mutants are not required.

Transformation protocols using the heterologous phleomycin-resistance (ble) gene of Streptoalloteichus hindustanus [59-61] as a dominant selectable marker have been established for $C$. reinhardtii [62] and $V$. carteri [63]. The aminoglycoside 3 '-phosphotransferase VIII (aphVIII) gene of Streptomyces rimosus [64] has been used as a dominant marker in $C$. reinhardtii [65,66], G. pectorale [17], and $V$. carteri $[66,67]$. Additional dominant selectable markers have only been established in C. reinhardtii. The corresponding protocols utilize the R100.1 plasmid/bacteriophage T4/synthetic aminoglycoside adenyltransferase (aadA) gene [68], the Streptomyces hygroscopicus aminoglycoside phosphotransferase (aph7”) gene [69], the mutated version of the protoporphyrinogen oxidase (PPX1) gene [70], the $C$. reinhardtii acetolactase synthase $(A L S)$ gene [71], and the mutated version of the $C$. reinhardtii ribosomal protein gene $S 14$ (CRY1) [72].

Among the dominant selectable markers described above, only the aphVIII gene $[17,65-67]$ and the ble gene 
$[62,63]$ have been used successfully for the transformation of more than one volvocine algae species. We decided to use the aphVIII gene because it was successfully used in three volvocine species. Furthermore, the aphVIII gene encodes an enzyme and not simply a binding protein like Ble, which requires a 1:1 ratio of expressed protein and antibiotic molecules. A heterologously expressed enzyme should allow for selection even in the event of a low expression rate.

Selectable marker genes need to be expressed homogeneously in transgenic organisms using (strong) promoters. Therefore, established molecular tools for volvocine algae routinely utilize promoters of highly expressed endogenous genes. For example, the promoters of the ribulose bisphosphate carboxylase small chain (RBCS2) gene [62], the PSAD gene of photosystem I [73], a fused promoter containing part of the heat shock protein 70A (HSP70A) promoter and part of the RBCS2 promoter [74], and another fused promoter containing part of the heat shock protein 70A $(H S P 70 A)$ promoter and part of the $\beta_{2}$-tubulin promoter $\left(\beta_{2} T U B\right)$ [74] have been utilized in C. reinhardtii. For $V$. carteri, the $\beta$ tubulin promoter [75], the promoter of the arylsulfatase (ars) gene [76,77], and a $h s p 70 \mathrm{~A} / r b c \mathrm{~S} 3$ fusion promoter [67] have been established. Because E. elegans has not been sequenced and because there were no endogenous promoter sequences available, we intended to test heterologous promoters. Though promoter sequences are frequently species-specific, it has been shown that some promoters also work in related volvocine species $[17,66]$.

Research with transgenic organisms also requires reporter genes. Genes encoding the green fluorescent protein $(g f p)$ of Aequorea aequorea [78], the arylsulfatase (ars) gene of $V$. carteri [77], the hexose $/ \mathrm{H}^{+}$symporter (hup1) gene of Chlorella kessleri [75], and the luciferases of Renilla reniformis (rluc) [79,80] and Gaussia princeps (gluc) $[17,81,82]$ have been used successfully in volvocine algae (mainly C. reinhardtii and $V$. carteri). For experiments in Eudorina, a codon-adapted version of the G. princeps luciferase gene seemed suitable because luciferase exhibits a very high enzymatic activity even when expressed at low levels [82]. Additionally, luciferase can be used for large-scale screening by a simple enzymatic assay, and it has been shown to work in two volvocine species, C. reinhardtii [82] and G. pectorale [17].

Here, we demonstrate the stable nuclear transformation of $E$. elegans by particle bombardment using a chimeric, aphVIII-based selectable marker gene driven by a tandem promoter of $V$. carteri. In addition, we demonstrate the expression of a heterologous reporter gene, the codonoptimized luciferase gene of G. princeps, driven by promoters of C. reinhardtii or $V$. carteri.

\section{Results}

\section{Antibiotic tolerance of wild-type Eudorina algae}

The lowest concentration of the antibiotic paromomycin that still kills all wild-type Eudorina cells was determined to allow for selection of transformants with potentially weak transgene-mediated resistance. To investigate the paromomycin tolerance of the wild-type E. elegans strain, identical numbers of cells were exposed to increasing concentrations of paromomycin, incubated for 10 days, and screened for living (green) or dead (white) cells. A concentration of $0.20 \mu \mathrm{g}$ paromomycin/ml or higher led to $100 \%$ cell death (Figure 2A, left panel). Processing of large-scale screenings of culture plates was facilitated by creating redshifted, false-color images from standard photographs of the plates; this conversion allows for an objective and rapid discrimination between wells containing living cells and wells containing dead cells (Figure 2A, right panel).

\section{Transformation experiments using an aphVIII-based selectable marker}

For the transformation of E. elegans, a chimeric, aphVIIIbased plasmid (pPmr3) [67] was used as a selectable marker. The pPmr3 plasmid contains the coding sequence of the original $S$. rimosus aphVIII gene, a $5^{\prime}$-flanking sequence that includes an artificial tandem promoter from the $h s p 70 \mathrm{~A}$ and $r b c \mathrm{~S} 3$ genes of $V$. carteri, and a $3^{\prime}$ flanking sequence derived from the $r b c \mathrm{~S} 3$ gene of $V$. carteri (Figure 3A).

Transformation of wild-type E. elegans cells was performed using a Biolistic ${ }^{\circledR}$ PDS-1000/He particle gun and DNA-coated gold microprojectiles [17]. For the transformation, approximately $3 \times 10^{5}$ logarithmically growing Eudorina algae were harvested by centrifugation; this corresponds to approximately $9 \times 10^{6}$ target cells. The algae were immobilized on a membrane filter, and excess liquid was removed. During development of the transformation protocol, transformation parameters were modified until paromomycin-resistant transformants were obtained (see below). The protocol was then modified to increase the number of transformants. The most successful combination of parameters for transformation of E. elegans is summarized in Additional file 1. The transformation protocol included the use of microprojectiles with a diameter of $0.6 \mu \mathrm{m}$, which were coated with $5 \mu \mathrm{g}$ of the selectable marker plasmid pPmr3 and, where applicable (see below), $5 \mu \mathrm{g}$ of a non-selectable, co-transformed plasmid. The burst pressure of the rupture discs was $1,100 \mathrm{psi}$, and the distance between the rupture disc and the macrocarrier was adjusted to $8 \mathrm{~mm}$. The distance between the macrocarrier and the stopping screen was set to $7 \mathrm{~mm}$, and the distance between the stopping screen and target cells was adjusted to $8 \mathrm{~cm}$. After a recovery phase of $24 \mathrm{~h}$ in standard liquid medium, the antibiotic resistant transformants were selected by the addition of paromomycin 


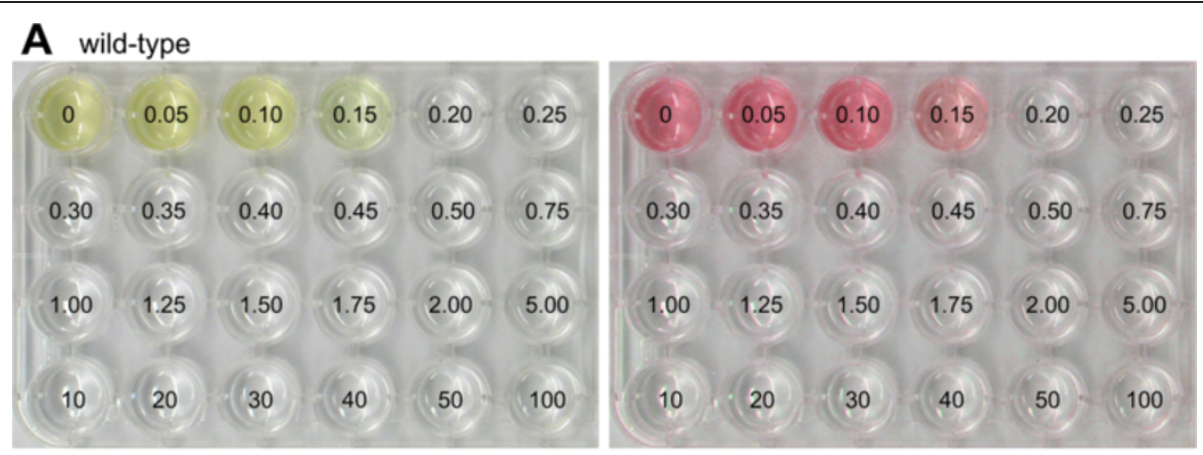

\section{B transformant EuTJ-14}
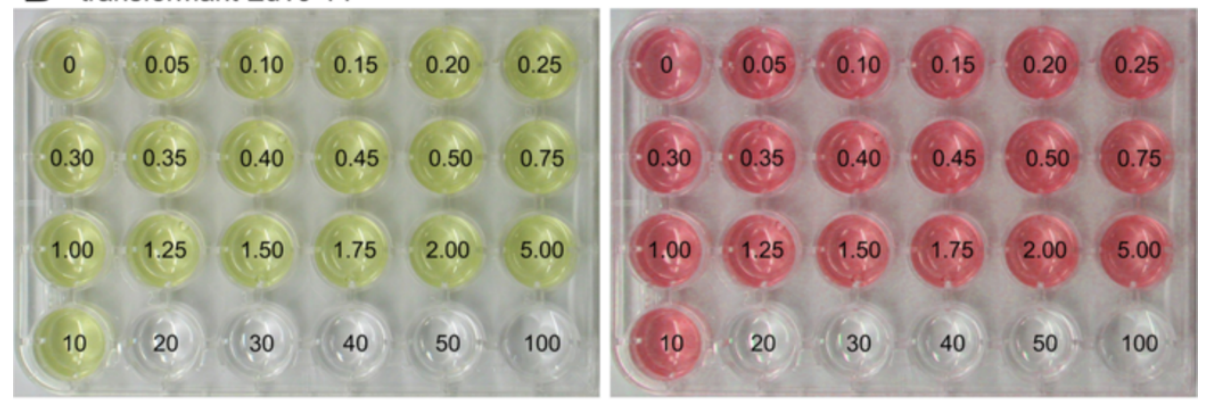

\section{C transformant EuHR-7}
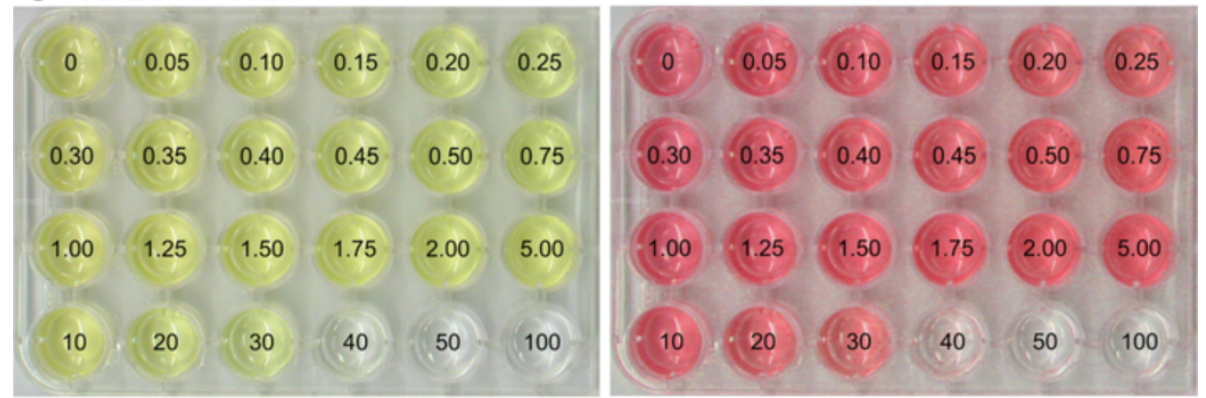

\section{D transformant EuHsp-5}
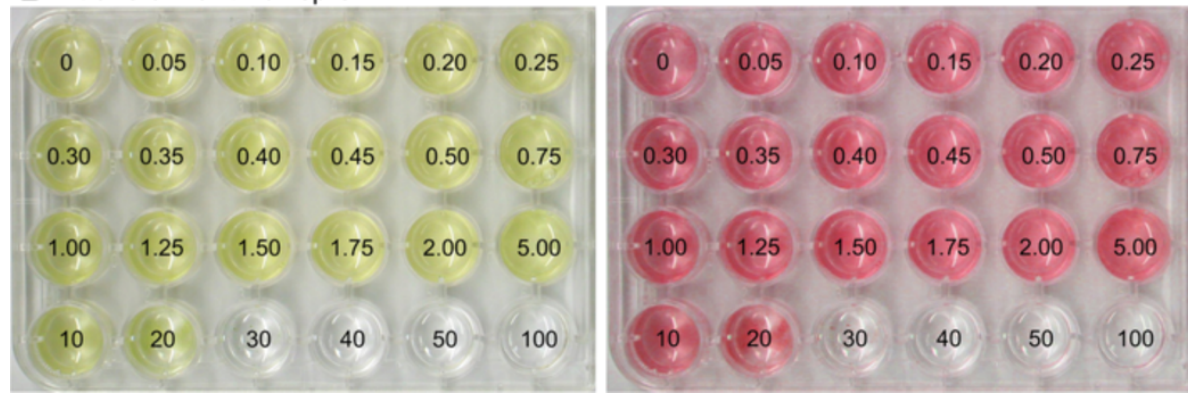

Figure 2 Analysis of paromomycin resistance in wild-type and transgenic E. elegans strains. For analysis of antibiotic resistance, identical quantities of wild-type or transgenic Eudorina cells were exposed to increasing concentrations of paromomycin, and incubated for 10 days. Numbers refer to the concentration of paromomycin $[\mu \mathrm{g} / \mathrm{ml}]$ utilized. Natural color (left) and red-shifted, false-color images (right) are shown. (A) Wild-type E. elegans strain UTEX 1193 used as a reference control. (B-D) Transgenic E. elegans strains co-transformed with pPmr3, the selectable marker plasmid, in addition to a second, non-selectable reporter gene plasmid. (B) Transformant EuTJ-14 was co-transformed with the plasmids pPmr3 and pPsaD-GLuc. (C) Transformant EuHR-7 was co-transformed with the plasmids pPmr3 and pHRLucP. (D) Transformant EuHsp-5 was cotransformed with the plasmids pPmr3 and pHsp70A-GLuc. 


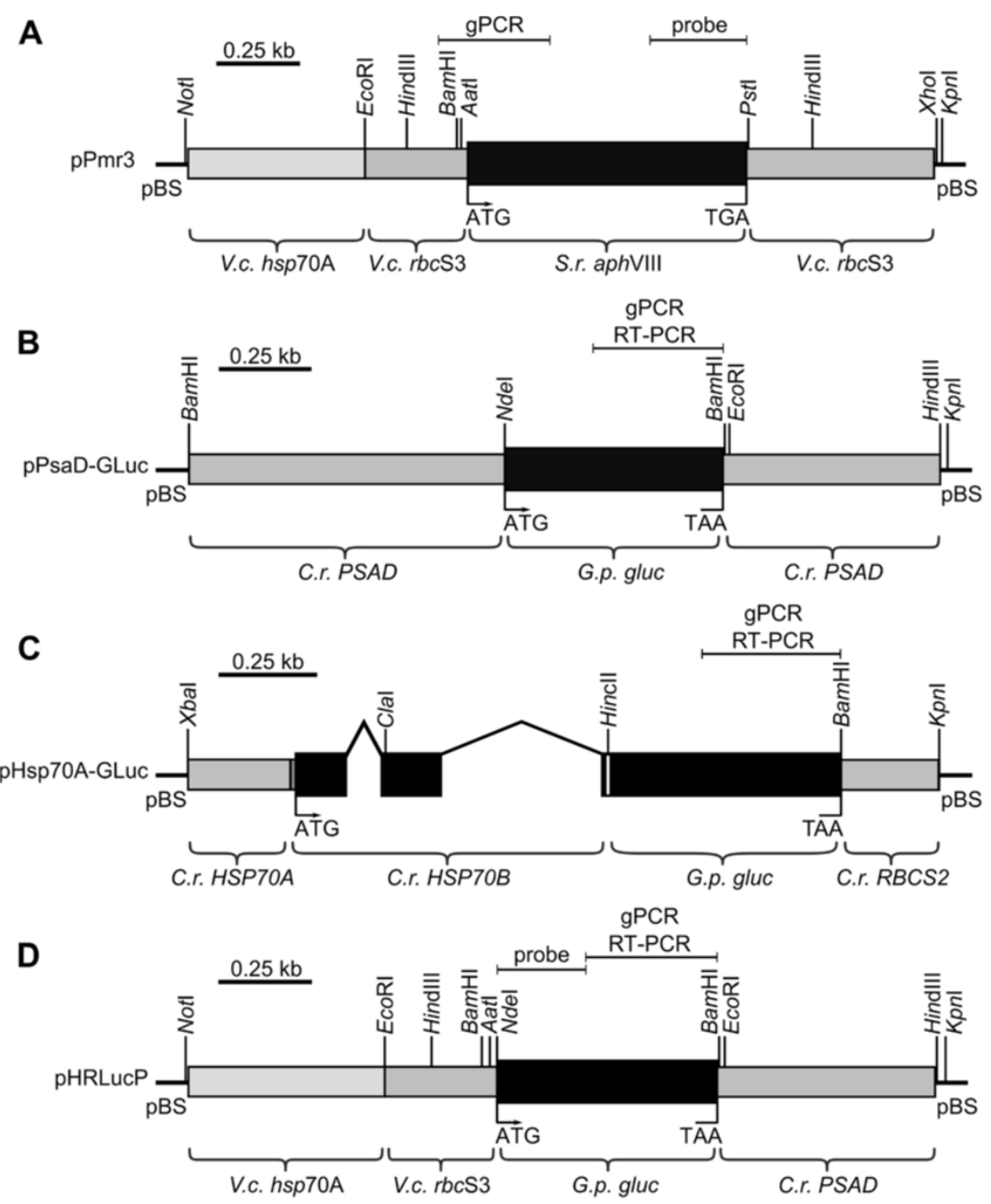

Figure 3 Schematic diagram of the selectable marker plasmid and co-transformed, non-selectable plasmids. (A) The chimeric selectable marker plasmid pPmr3. (B-D) Co-transformed, non-selectable plasmids containing reporter genes: (B) pPsaD-GLuc, (C) pHsp70A-GLuc, and (D) pHRLucP. The angled lines in (C) indicate introns. (A-D) Amplified genomic (GPCR) or RT-PCR fragments as well as probes used for Southern blots are indicated. V.c., Volvox carteri; C.r., Chlamydomonas reinhardtii; S.r., Streptomyces rimosus; G.p., Gaussia princeps; gluc, luciferase gene, pBS, pBluescript II vector.

$(2 \mu \mathrm{g} / \mathrm{ml})$. It should be noted that all transformants exhibited the same morphological phenotype as their wild-type parental strain. The detailed transformation protocol is provided in the Methods section. After establishing the transformation protocol, each transformation experiment yielded approximately $3-12$ antibiotic resistant clones.

\section{Antibiotic resistance of transformants}

Transformants from five independent transformation experiments (i.e., 33 clones) were tested for their maximal antibiotic resistance. The paromomycin resistance of the clones varied, with a wide range from 5 to $50 \mu \mathrm{g} /$ $\mathrm{ml}$ (Figure 2B-D; also see Additional file 2); however, there was little variation for a given clone. The transformants with the lowest resistance to paromomycin treatment were capable of surviving in 33-fold higher concentrations of paromomycin than parental wild-type strains, which tolerated only up to $0.15 \mu \mathrm{g}$ paromomycin/ $\mathrm{ml}$. The transformants with the most robust resistance tolerated concentrations of antibiotic up to 333-fold higher than the wild-type strains. The variation in resistance between different clones could reflect position effects on 
expression of the transgene due to random integration or could reveal gene-dosage effects caused by variable number of copies integrated into the genome.

\section{Stable integration of plasmid DNA into the genome of transformants}

The stable integration of the selectable marker gene (encoded on the pPmr3 plasmid) into the genome of the 33 clones from five independent transformation experiments was verified by PCR using aphVIII-specific oligonucleotide primers (Figure 4A4) and genomic DNA as the template. A PCR fragment of the expected size was obtained from all paromomycin-resistant clones; as expected, the parental wild-type strain failed to produce this fragment (Figure 4A1-A3). The PCR fragment was verified by sequencing (Figure 4A4).
In addition, genomic DNA from transformants and from the parental wild-type strain was analyzed by Southern blot for integration of the aphVIII gene into the genome. A fragment of the aphVIII coding region (Figure 3A) was used as a probe for the Southern blot. Hybridization signals were detectable only in transformants and not for the parental strain. A Southern blot result for two randomly chosen transformants and the parental wild-type is shown in Figure 4B. Based on the sequence of pPmr3, a hybridization signal of $1.2 \mathrm{~kb}$ was expected following digestion with HindIII, and this fragment was observed following the digestion of transformant genomic DNA. At least two additional bands were detectable in HindIII-digested samples, which could indicate additional incomplete or fragmented integration of the selectable marker plasmid (Figure 4B). The pPmr3 plasmid contained only a single BamHI site. Therefore,

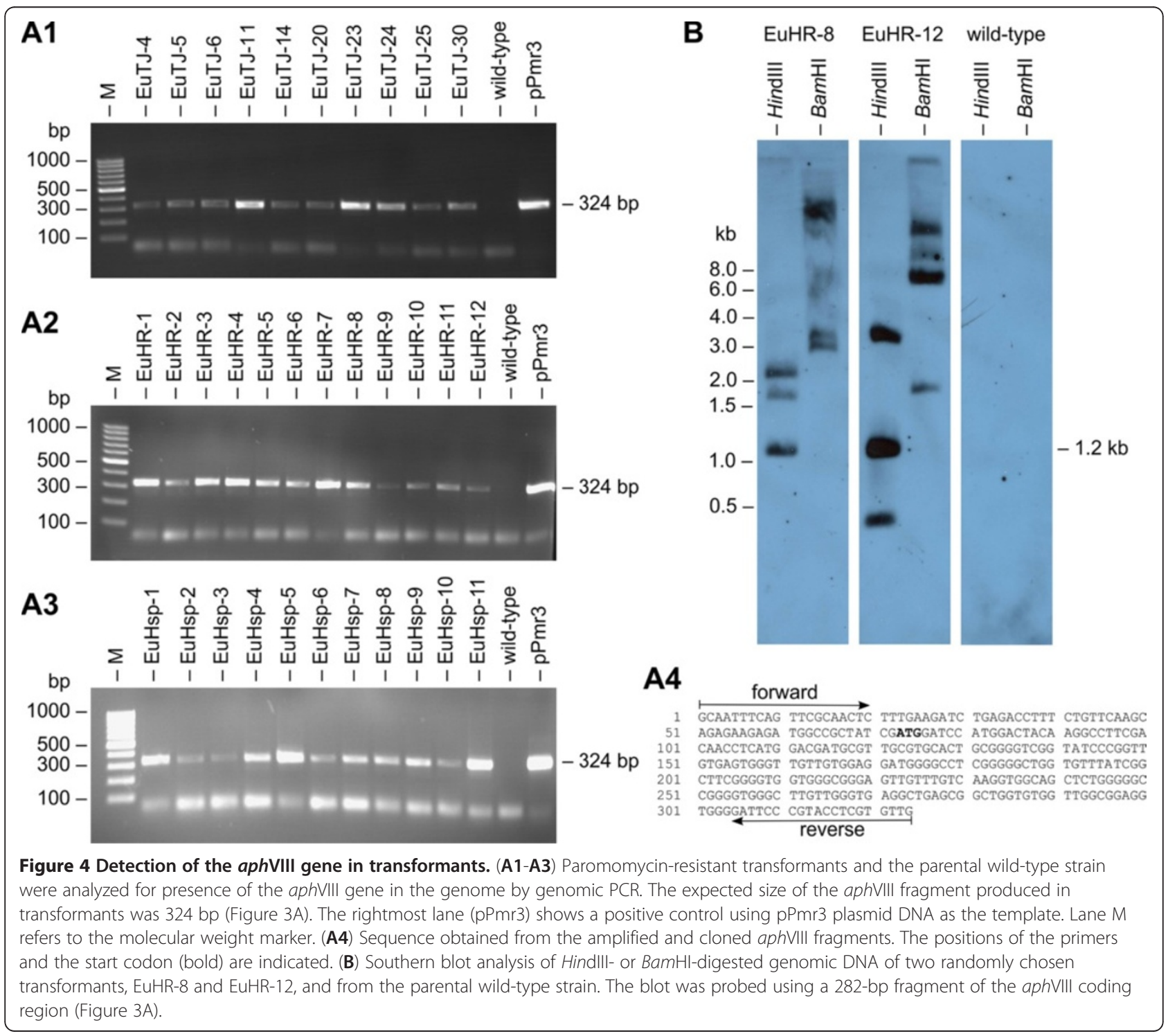


the second BamHI site of the BamHI fragments must be located within the genomic sequence flanking the integrated plasmid, and detection of more than one BamHI hybridization signal indicates multiple integration events in different areas of the genome. Up to five signals were detected in BamHI-digested genomic DNA of transformants, which indicates that up to five integration events occurred (Figure 4B). However, several of these pPmr3 fragments may contain an incomplete selectable marker gene as indicated by the HindIII digests. The antibiotic resistance of transformants demonstrates that at least one copy of the selectable marker gene is complete. The Southern blot experiments indicate that particle gun transformation of E. elegans often leads to more than one integration event, but the number of integration events is quite low (5 or fewer events).

\section{Calculation of transformation frequency}

The frequency of transformation was calculated as the ratio between the number of transformants that exhibited both antibiotic resistance and the correct aphVIII fragment following PCR and the total number of cells used for each transformation experiment $\left(9 \times 10^{6}\right.$ cells). Based on 5 independent transformation experiments, the transformation frequency was calculated as $3.7 \times 10^{-7}$ $( \pm 14 \%)$ transformants per cell. Assuming that all of the E. elegans colonies used for transformation contained 32 cells, the calculated transformation frequency corresponds to $1.2 \times 10^{-5}( \pm 14 \%)$ transformants per organism.

\section{Stable co-transformation with non-selectable reporter gene plasmids}

Construction of transformation vectors with selectable markers and non-selectable genes of interest in the same plasmid is frequently hampered by the large size of the final plasmid and by inappropriate positions of required restriction sites. Therefore, selectable markers and genes of interest have been frequently introduced on different plasmids by co-transformation of volvocine species $[17,46,62,63,67,69,75,77,83]$.

To investigate the efficiency of co-transformation in Eudorina, we used pPmr3 as a selectable marker plasmid, which contains the aphVIII gene, in conjunction with one of three different non-selectable reporter gene plasmids. The non-selectable reporter plasmids contain the gluc reporter gene from the G. princeps copepod, which was previously engineered to match the codon usage of C. reinhardtii [82], and different heterologous flanking sequences including promoters from C. reinhardtii and $V$. carteri. The pPsaD-GLuc plasmid contains the gluc gene, a $5^{\prime}$-flanking sequence of the $C$. reinhardtii PSAD gene (including the PSAD promoter and the $5^{\prime}$-UTR), and a $3^{\prime}$-flanking sequence from the PSAD gene (including the $3^{\prime}$-UTR) [82] (Figure 3B). The
pHsp70A-GLuc plasmid contains a $5^{\prime}$-flanking sequence from the $C$. reinhardtii $H S P 70 A$ gene, which includes the HSP70A promoter and the $5^{\prime}$-UTR [82] (Figure $3 \mathrm{C}$ ). This sequence is fused to a genomic fragment of the $C$. reinhardtii $H S P 70 B$ gene, which contains the first two exons and a small part of the third exon of HSP70B. The fragment also contains the two original introns of the $H S P 70 B$ gene, and the exons of the HSP7OB fragment encode the chloroplast transit peptide of HSP70B [84]. The gluc gene is fused downstream of the HSP7OB sequence, and gluc is followed by the $3^{\prime}$-flanking sequence of the C. reinhardtii RBCS2 gene, which includes the $3^{\prime}$ UTR (Figure 3C). The pHRLucP plasmid contains the gluc gene flanked by a $V$. carteri $h s p 70 \mathrm{~A} / r b c \mathrm{~S} 3$ hybrid sequence on its $5^{\prime}$-side; this sequence includes the $h s p 70 \mathrm{~A} / r b c \mathrm{~S} 3$ tandem promoter and a $5^{\prime}$-UTR. On the $3^{\prime}$-side of the gluc gene, the 3 '-flanking sequence of the C. reinhardtii PSAD gene follows, which includes the $3^{\prime}$ UTR (Figure 3D). Both the C. reinhardtii HSP70A promoter in the pHsp70A-GLuc plasmid and the $V$. carteri $h s p 70 \mathrm{~A}$ part of the tandem promoter in the pHRLucP plasmid are known to increase transcription following a period of elevated temperature.

The wild-type E. elegans strain was co-bombarded with the selectable marker plasmid (pPmr3) and with one of the non-selectable plasmids (pPsaD-GLuc, pHsp70A-GLuc, or $\mathrm{pHRLucP}$ ) (Figure 3B-D). The presence of the cobombarded plasmids in the genome of the transformants was verified by PCR using gluc-specific oligonucleotide primers and genomic DNA as the template. The expected PCR fragment of gluc (Figure 3B-D) was detected in almost all of the paromomycin-resistant transformants (Figure 5A1-A3), and the identity of the PCR fragment was verified by sequence analysis (Figure 5A4). In detail, five cotransformation experiments with $\mathrm{pPmr} 3$ and the nonselectable plasmids pPsaD-GLuc, pHsp70A-GLuc, and pHRLucP yielded 10, 11, and 12 paromomycin-resistant transformants, respectively. Of these, 6 (pPsaD-GLuc), 11 (pHsp70A-GLuc), and 12 (pHRLucP) transformants contained the non-selectable reporter genes. Based on these results, the co-transformation rate was calculated to be $50-100 \%$.

Moreover, the stable integration of the gluc gene into the genome of Eudorina as well as the copy number of the integrations was investigated by Southern blot analyses using a gluc-specific probe. The Southern blot results for two randomly chosen transformants are shown in Figure 5B. For hybridization experiments with HindIII-digested genomic DNA from co-transformants, a DNA fragment of $1328 \mathrm{bp}$ was expected, and fragments were detected in co-transformants. Likewise, hybridization to BamHI-digested DNA was expected to produce a $603 \mathrm{bp}$ fragment, and this fragment was detected in the genomic DNA of transformants (Figure 5B). In 


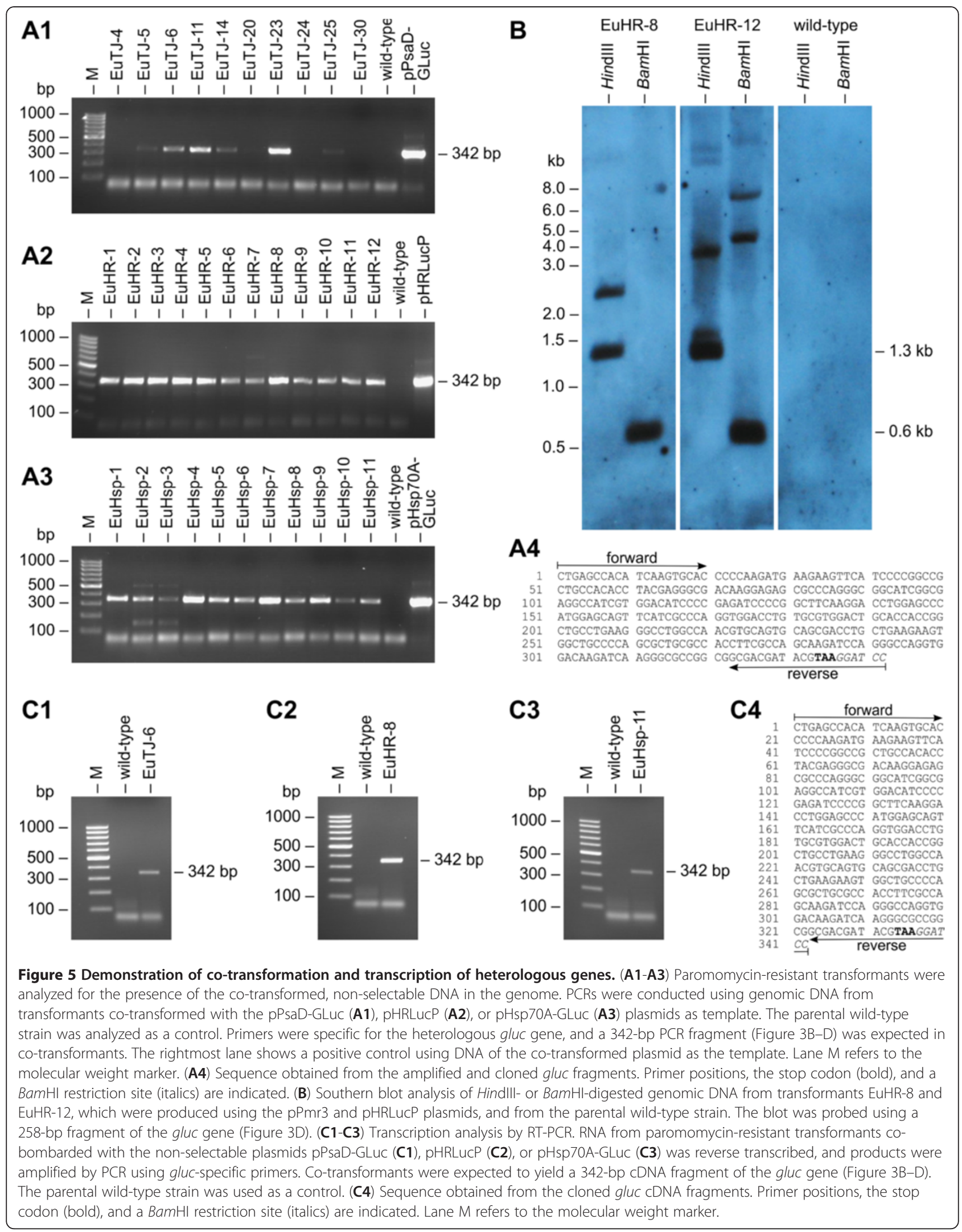


A luciferase activity of pPsaD-GLuc-derived transformants

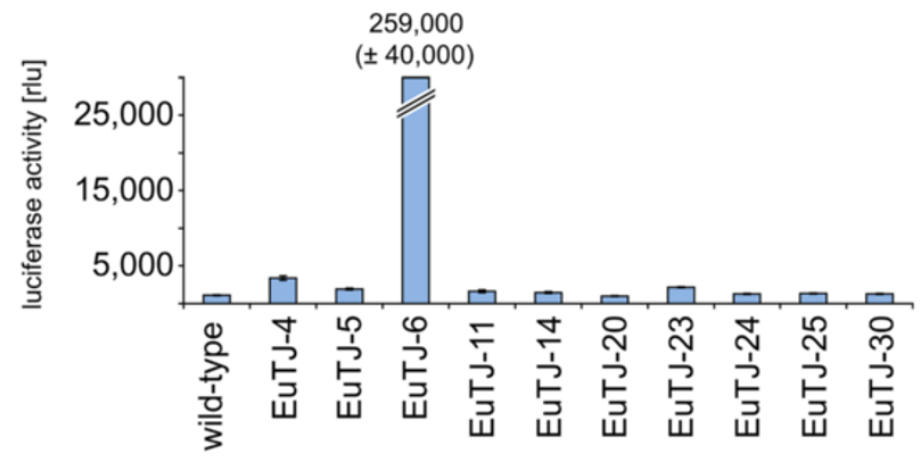

B luciferase activity of pHRLucP-derived transformants

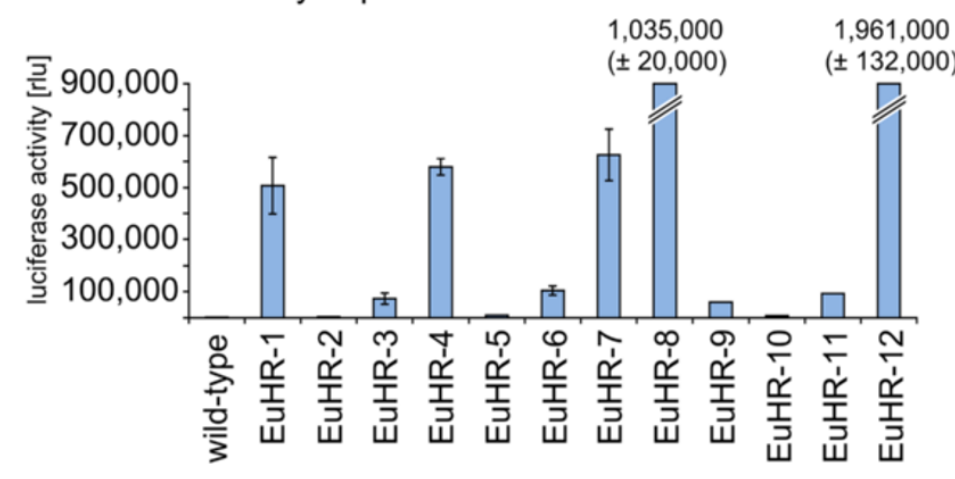

C luciferase activity of pHsp70A-GLuc-derived transformants

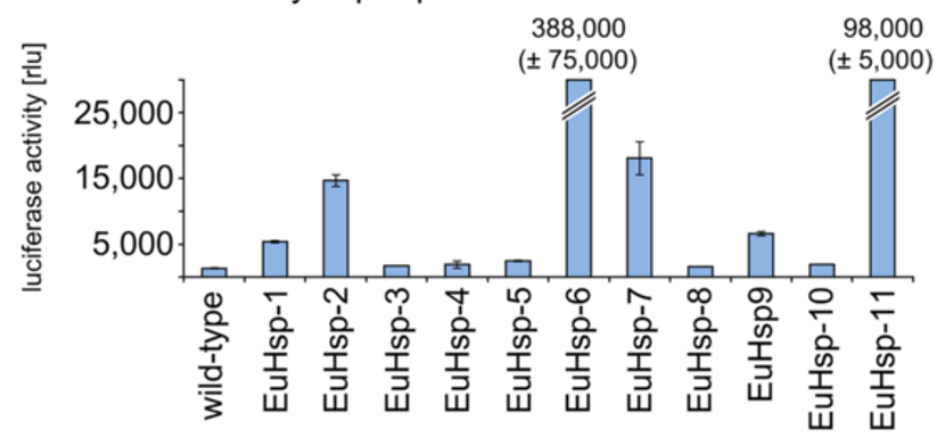

D fold induction of luciferase activity after heat shock

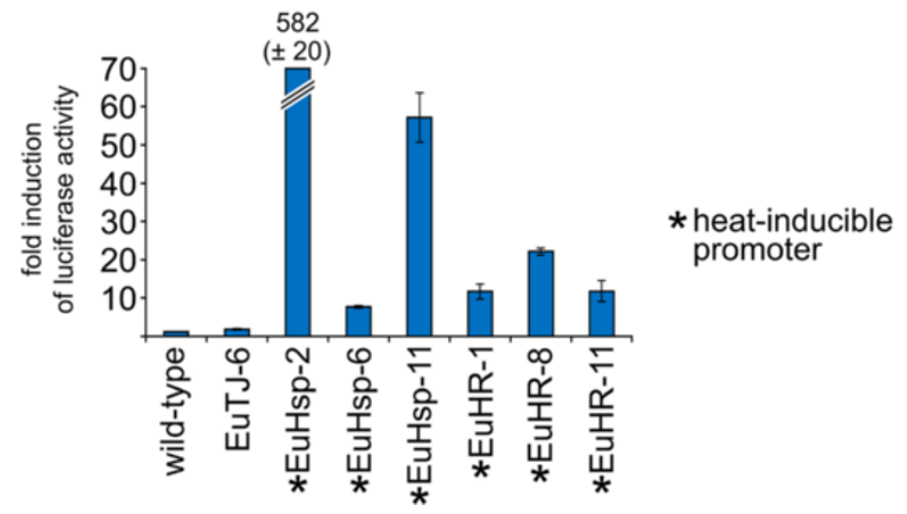

Figure 6 (See legend on next page.) 


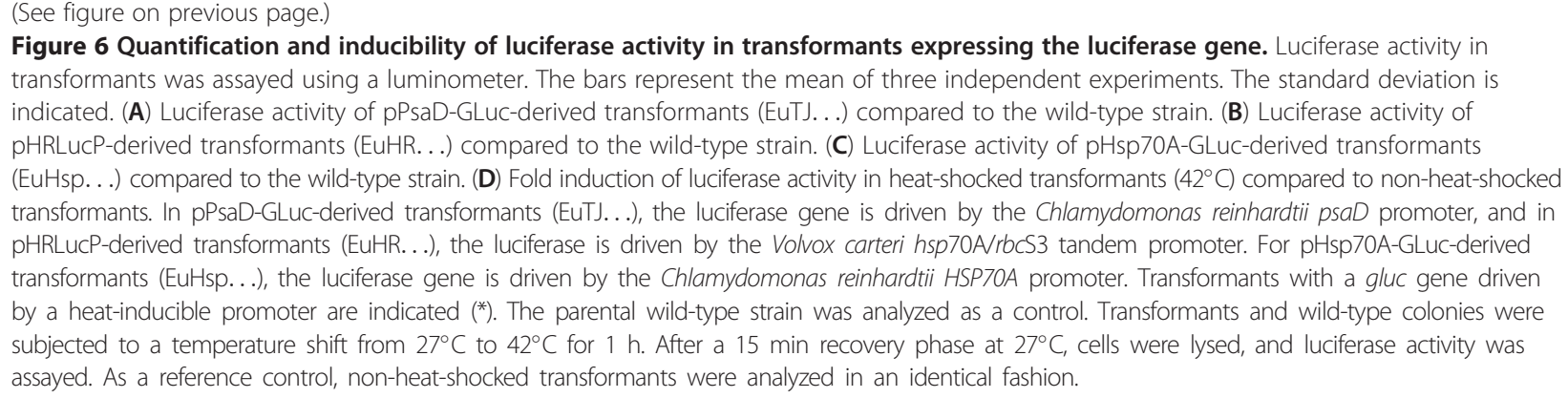

addition, hybridization signals of various sizes were detected in several co-transformants (e.g., EuHR-12 in Figure 5B), indicating additional integration of reporter gene fragments. However, the number of these fragment integrations was below five.

\section{Transcription of co-transformed, non-selectable reporter genes}

Total RNA of the transformants and gluc-specific oligonucleotide primers were used for RT-PCR to investigate the transcription of the heterologous gluc gene under the control of heterologous promoters from $V$. carteri and $C$. reinhardtii in transgenic in E. elegans strains. A 342-bp cDNA fragment of gluc was expected following RT-PCR (Figure 3B-D). The gluc cDNA fragments were obtained from transformants that contained the chimeric gluc genes following co-transformation with the pPsaD-GLuc, pHRLucP, and pHsp70A-GLuc plasmids (Figure 5C1-C3). The identity of the RT-PCR fragments was verified by sequence analysis (Figure 5C4). As expected, wild-type parental strains did not produce this fragment (Figure 5C1C3). Thus, the chimeric, non-selectable gluc reporter gene was successfully transcribed in E. elegans transformants under the control of various heterologous promoters from $V$. carteri and C. reinhardtii.

\section{Analysis of heterologous protein expression in co- transformants}

All transformants that contained the co-transformed gluc-construct in their genomes were analyzed for functional expression of the luciferase enzyme. The parental wild-type strain was used as a negative control. A luminometer was used to quantify luciferase activity following cultivation of the strains under standard conditions, and luminescence values were recorded as relative light units (rlu) (Figure 6A-C).

Among those that were co-transformed with the pPsaDGLuc plasmid, only a single co-transformant, EuTJ-6, exhibited strong luciferase activity $(259,000 \pm 40,000 \mathrm{rlu})$ (Figure 6A). The parental wild-type strain only produced a very low background value $(1,100 \pm 30 \mathrm{rlu})$.
Contrary to the result with pPsaD-GLuc co-transformants, several pHRLucP co-transformants exhibited strong luciferase activity (Figure 6B). Like in the previous experiment, the background value of the wild-type strain was very low $(1,100 \pm 50 \mathrm{rlu})$. It should be noted that the luciferase activity levels in co-transformants were quite variable. For example, the enzymatic activity of cotransformants EuHR-2 (4000 \pm 90 rlu $)$ and EuHR-12 $(1,961,000 \pm 132,000 \mathrm{rlu})$ differed by a factor of nearly 500 (Figure 6B). The luciferase activity in the EuHR-12 strain was the highest luciferase activity detected among all transformants generated using the gluc gene (when cultured under standard conditions).

Also among the co-transformants produced using the pHsp70A-GLuc plasmid, several strains exhibited strong luciferase activity (Figure 6C). The lowest activity was detected in co-transformant EuHsp-1 (5,400 $\pm 170 \mathrm{rlu})$, and the highest activity was observed in EuHsp-6 (388,000 \pm $75,000 \mathrm{rlu})$. The enzymatic activity of pHsp70A-GLuc cotransformants differed by a factor of about 70 .

In all luciferase-expressing co-transformants, the enzymatic activity was stable. Thus, even the extreme variability in luciferase activity between different transformants was permanent.

\section{Inducibility of heterologous protein expression}

Inducible promoters are useful tools in gene technology, and the heat shock promoters used here are induced at elevated temperatures, at least in the species where they originate. To investigate the inducibility of the $V$. carteri $h s p 70 A / r b c S 3$ promoter of the pHRLucP plasmid (Figure 3D) and the $C$. reinhardtii HSP70A promoter of the pHsp70A-GLuc plasmid (Figure 3C), which drive the gluc gene in transgenic E. elegans, the corresponding transformants were exposed to elevated temperatures, and the luciferase activity was measured. Thus, cultures were incubated at different temperatures ranging from $27^{\circ} \mathrm{C}$ to $57^{\circ} \mathrm{C}$ (for $1 \mathrm{~h}$ ). Cultures were then allowed to recover at $27^{\circ} \mathrm{C}$ (for $15 \mathrm{~min}$ ), harvested by centrifugation, and disrupted by sonification, and finally, the luciferase activity was measured in a luminometer. Induction factors were calculated by comparing 
luminescence values with untreated, reference cultures of the same strain; reference cultures were kept at standard conditions $\left(27^{\circ} \mathrm{C}\right)$. The strongest luciferase activity induction was achieved in cultures that were incubated at $42^{\circ} \mathrm{C}$ (see Additional file 3). The highest induction factor obtained at $42^{\circ} \mathrm{C}$ was $582( \pm 20)$ and was observed in a strain generated by co-transformation with the pHsp70A-GLuc plasmid (EuHsp-2, Figure 6D). Transformants generated by co-transformation with pHRLucP revealed an up to 22 ( \pm 1)-fold induction (EuHR-8, Figure 6D). The wild-type strain and the transformants generated with the pPsaD-GLuc plasmid, which does not contain a heat-inducible promoter, exhibited no induction of luciferase activity, as expected (wild-type and EuTJ6, Figure 6D). Thus, both the HSP70A-promoter of C. reinhardtii and the $h s p 70 \mathrm{~A}$ promoter of $V$. carteri are heatinducible even when utilized in E. elegans.

We investigated the detection of light in heat-induced transformants using a digital camera and a light-sensitive film in order to optimize the assay for high-throughput setups. Logarithmically growing cultures were divided into two cultures, and one was subjected to temperature of $42^{\circ} \mathrm{C}$. The other was maintained at $27^{\circ} \mathrm{C}$ as described above. Following cell lysis, the transformants were assayed for luciferase activity in 24-well tissue culture plates (Figure 7A, B). The bioluminescence of heat-shocked transformants was not only strong enough to generate a signal on light-sensitive film (Figure 7A, B), but the luminescence was also visible to the naked eye in the dark room and detectable by a standard digital camera (Figure 7A, B).

\section{In-gel activity assays}

The utility of a heterologous reporter gene in E. elegans would increase if the gene product could be easily detected even in raw cell extracts after separation on standard SDS-PAGE, which could allow for simple detection and size determination of fusion proteins that contain the Gluc reporter. For the expression product of the gluc gene encoded by the pHRLucP plasmid, an expected molecular weight of $21 \mathrm{kDa}$ was calculated based on the amino acid sequence of the Gluc protein. For the HSP70B/Gluc fusion protein encoded by pHsp70A-GLuc, which contains the HSP70B chloroplast transit peptide, an expected molecular mass of $31 \mathrm{kDa}$ was calculated.

Protein extracts of transformants generated by cotransformation with the pHRLucP or pHsp70A-GLuc plasmid were separated by standard SDS-PAGE [85] without using thiol reagents. After electrophoresis, ingel renaturation of luciferase was achieved in the presence of $\beta$-cyclodextrin, a cyclic oligosaccharide [86]. The renatured enzyme was assayed in the gel by addition of the substrate and detection of bioluminescence on lightsensitive film. In these in-gel-luciferase activity assays, co-transformants generated with the pHRLucP plasmid exhibited strong luciferase signals of the expected size ( $21 \mathrm{kDa})$ (Figure 8A). Co-transformants generated with

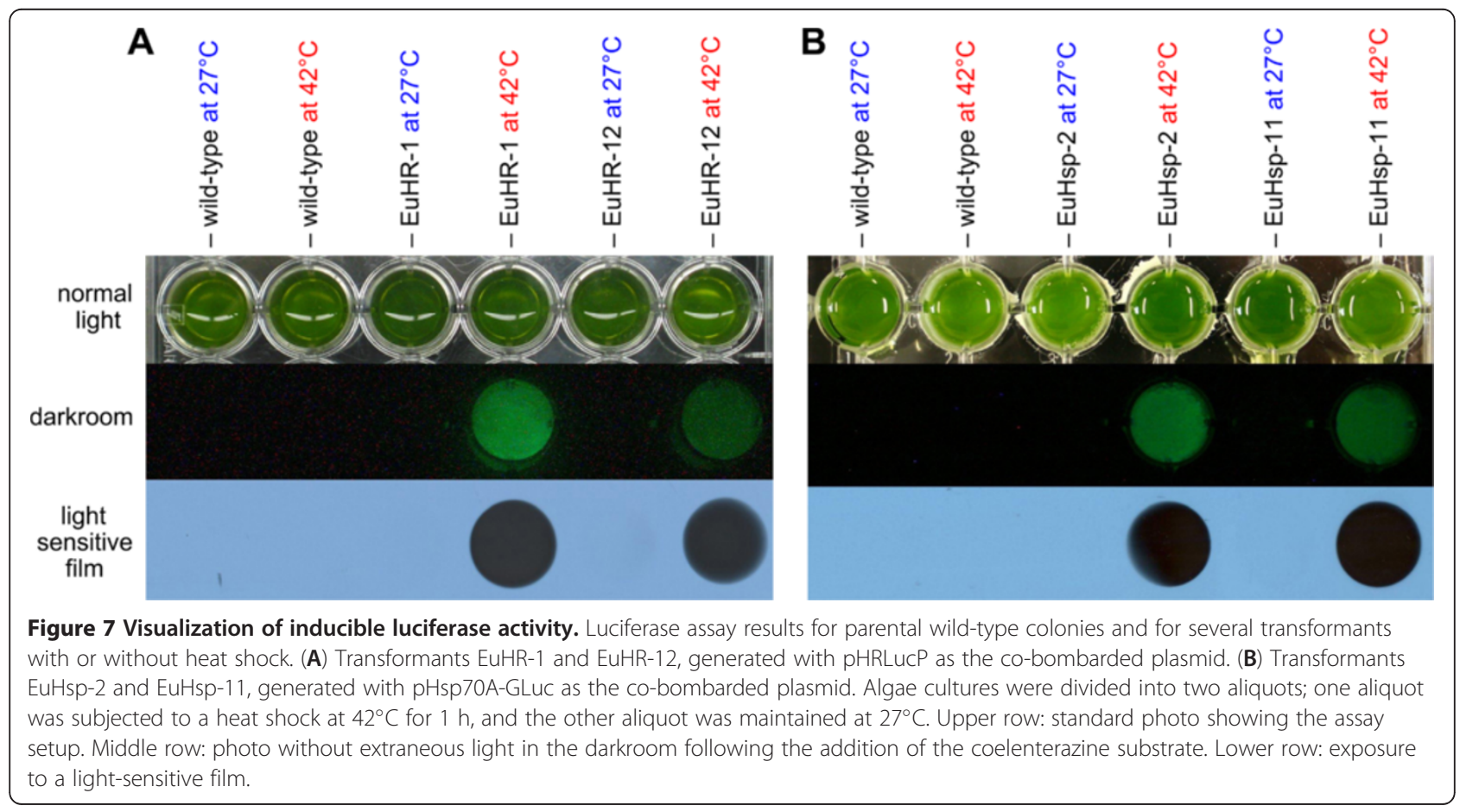




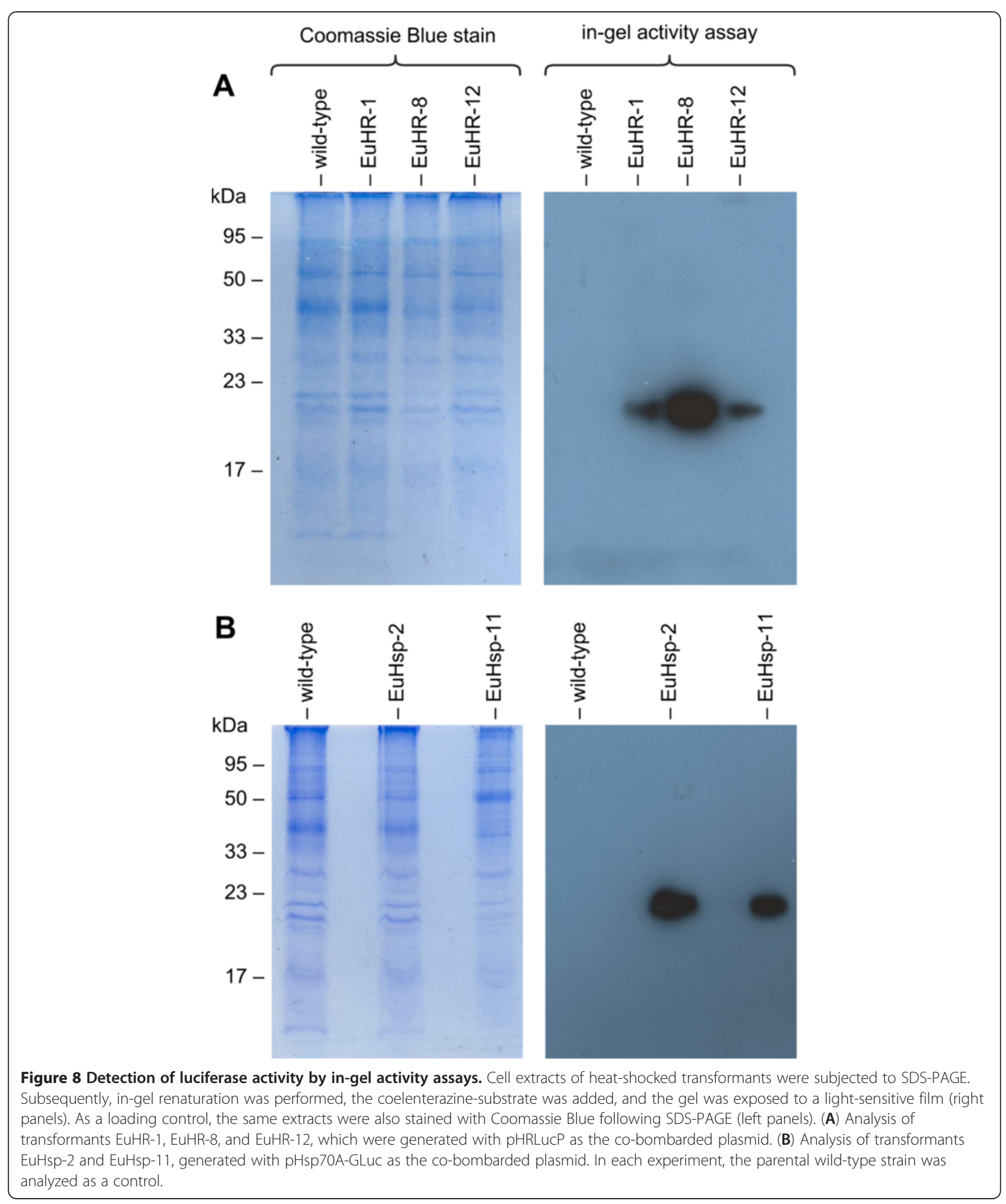


pHsp70A-GLuc also showed strong signals of approximately $21 \mathrm{kDa}$ (Figure $8 \mathrm{~B}$ ), indicating that the heterologous HSP70B chloroplast transit peptide of $C$. reinhardtii is cleaved in E. elegans.

\section{Long-term stability of DNA integration and gene expression}

The long-term stability of transgenes, which have been randomly integrated into the genome, and the perpetuation of their expression are beneficial for any genetically engineered organism.

The stability of the aphVIII and gluc transgenes within the genomes of transgenic E. elegans strains was investigated by re-examining the 33 transformants for resistance to paromomycin and luciferase activity after 12 months without any selective pressure, which reflects 300 generations of cultivation. Even after this period, the resistance of the transformants to paromomycin, which was determined at the highest possible antibiotic concentrations, varied by only approximately $\pm 5 \%$ from the values determined at the initial time-point (see above). Likewise, the luciferase activity in transformants differed from the initial values by only approximately $\pm 6 \%$. Thus, the integration and expression of the heterologous aphVIII and gluc genes are stable in E. elegans.

\section{Discussion}

Stable nuclear transformation of E. elegans is now feasible using a chimeric selectable marker from a heterologous source. Additionally, chimeric reporter gene constructs and constitutive and inducible promoters are provided without using endogenous genes or DNA elements. We also demonstrate that inducible, heterologous promoters can retain their inducibility in the new cellular environment of the target species.

The frequency of transformation for E. elegans was estimated to be $3.7 \times 10^{-7}$ transformants per cell. A comparable value of $1.1-6.6 \times 10^{-7}$ transformants per cell has been reported for the related G. pectorale species [17]. The transformation frequency in C. reinhardtii was calculated as $1.3-1.9 \times 10^{-7}$ transformants per cell [87], which is similar to the values above. In $V$. carteri, the transformation frequency was calculated per organism and not per cell; this value was reported to be $2.5 \times 10^{-5}$ [44]. The authors used a $V$. carteri mutant, which carries a mutation that causes somatic cells to redifferentiate as asexual reproductive cells. If approximately 200 of the 2000-4000 cells composing this mutant actually reproduced, the estimated transformation frequency per cell would be approximately $1.25 \times 10^{-7}$, which is similar to the rates mentioned above. Thus, the reported transformation frequencies for all of the investigated volvocine species appear to be quite similar.
Co-transformation of a selectable marker plasmid and the gene of interest on a separate plasmid is a convenient strategy for dealing with large genes and complex gene constructs $[17,46,62,63,67,69,75,77,83]$. Moreover, the same selectable marker plasmid can be used for all transformation experiments. The co-transformation rate in E. elegans was determined to be $50-100 \%$. For $V$. carteri, rates of $10-60 \%$ [63] or $40-80 \%$ [44] have been reported. The co-transformation rates for $C$. reinhardtii are $50 \%$ [88] or approximately $80 \%$ [63], and a cotransformation rate of $30-50 \%$ [17] has been reported for G. pectorale. However, the varying co-transformation rates reported for different volvocine species may not represent species-specific values, but they could be the result of different plasmid sequences, plasmid sizes, or (co-)transformation conditions. Although the co-transformation rates vary over a wide range in volvocine algae $(10-100 \%)$, all rates are quite high, and therefore, co-transformation can be used routinely in all volvocine species. Even the lowest rate of $10 \%$ means that one co-transformant with the gene of interest can be identified from only ten antibiotic-resistant transformants, which can be easily detected by PCR. Therefore, transformation of volvocine algae does not require construction of vectors that contain all required genes and regulatory elements on a single plasmid.

The transformation protocol for E. elegans described above can now also be used for insertional mutagenesis of the E. elegans genome, which has been done in $C$. reinhardtii $[89,90]$. Insertional mutagenesis is one of the most powerful methods for determining the cellular function of a particular gene. For insertional mutagenesis, the pPmr3 plasmid (Figure 3A) could be used as currently constructed; the plasmid only needs to be linearized (e.g., by digesting with the restriction enzymes NotI or KpnI). Fortunately, the number of integrated copies of the transforming plasmid was low in our E. elegans transformation experiments, and these values were comparable to the copy numbers reported for insertional mutagenesis studies in C. reinhardtii [89]. Insertional loss-of-function mutants can be screened for developmental or physiological phenotypes, and the disrupted genes flanking the transforming DNA can be amplified from insertional mutants using thermal asymmetric interlaced (TAIL)-PCR [91], sequenced, and characterized.

\section{Conclusions}

Both heterologous coding regions and promoters from related volvocine species work in E. elegans and drive both constitutive and inducible expression of heterologous genes. The availability of a transformation system, constitutive and inducible promoters, selectable markers, and reporter genes now makes extensive engineering of 
E. elegans possible. The results also demonstrate that genetic engineering of a species is possible even without endogenous genes and promoters.

\section{Methods}

\section{Strains and culture conditions}

The wild-type Eudorina elegans strain UTEX 1193 was obtained from R. Schmitt (University of Regensburg, Germany). Eudorina cultures were maintained in Volvox medium (VM) [92] at $27-29^{\circ} \mathrm{C}$ in an $8 \mathrm{~h}$ dark $/ 16 \mathrm{~h}$ light $(\sim 10,000$ lux $)$ cycle. Cultures were grown in $10 \mathrm{ml}$ glass tubes, 50 or $300 \mathrm{ml}$ Erlenmeyer flasks, or 1,000 ml Fernbach flasks. The glass tubes had caps that allow for gas exchange, and Erlenmeyer and Fernbach flasks were aerated via Pasteur pipettes with approximately $50 \mathrm{~cm}^{3}$ sterile air/min. Transgenic strains expressing the aphVIII gene were grown in VM in the presence of $1 \mu \mathrm{g}$ paromomycin $/ \mathrm{ml}$ (paromomycin sulfate, Sigma-Aldrich, St. Louis, MO).

\section{Transformation vectors}

The selectable marker pPmr3 plasmid (Figure 3A) is 5.1 $\mathrm{kb}$ in size and contains $0.77 \mathrm{~kb}$ of upstream sequence, which includes a $V$. carteri hsp70A-rbcS3 tandem promoter $(0.5 \mathrm{~kb}$ of $V$. carteri hsp70A and $0.27 \mathrm{~kb}$ of $V$. carteri $r b c \mathrm{~S} 3$ sequences), the $0.8 \mathrm{~kb}$ coding region of the $S$. rimosus aphVIII gene, the $3^{\prime}$-UTR from the $V$. carteri $r b c \mathrm{~S} 3$ gene $(0.53 \mathrm{~kb}$ of downstream sequence), and the pBluescript vector backbone [67] [GenBank: AY429514]. The pPsaD-GLuc plasmid (Figure $3 \mathrm{~B}$ ) is $5.0 \mathrm{~kb}$ in size and contains $0.8 \mathrm{~kb}$ of upstream sequence, which includes the $C$. reinhardtii PSAD promoter, the $0.57 \mathrm{~kb}$ coding region of the G. princeps gluc gene (optimized for the codon usage of $C$. reinhardtii), the 3 '-UTR of the C. reinhardtii PSAD gene $(0.56 \mathrm{~kb}$ of downstream sequence), and the pBluescript vector backbone $[73,82]$ [GenBank: EU372000, AF335592]. The pHsp70A-Gluc plasmid (Figure $3 \mathrm{C}$ ) is $4.9 \mathrm{~kb}$ in size and contains 0.26 $\mathrm{kb}$ of upstream sequence, which includes the $C$. reinhardtii HSP70A promoter, a $0.8 \mathrm{~kb}$ fragment of the $C$. reinhardtii $H S P 70 B$ genomic sequence (including two introns) fused to a $0.57 \mathrm{~kb}$ coding region of the codonoptimized G. princeps gluc gene, the $3^{\prime}$-UTR of the $C$. reinhardtii $R B C S 2$ gene $(0.22 \mathrm{~kb}$ of downstream sequence), and the pBluescript vector backbone [82]. For construction of the pHRLucP plasmid, a $1.2 \mathrm{~kb}$ DNA fragment containing the codon-optimized G. princeps gluc gene $(0.57 \mathrm{~kb})$ and the 3 '-UTR of the $C$. reinhardtii PSAD gene ( $0.56 \mathrm{~kb}$ of downstream sequence) was amplified by PCR using the following primers: $5^{\prime}$-TAGG CCTAACAAGCCCATATGGTC (ON15486) and $5^{\prime}-\mathrm{GG}$ AAACAGCTATGACCATG (M13-reverse); the pPsaDGLuc plasmid [82] was used as the template. Primer ON15486 contains an artificial AatI site (restriction site underlined; start codon in italics). The PCR fragment was cloned into the pGEM-T easy vector (Promega, Madison, WI) and cut out with AatI and KpnI; the latter restriction site comes from the cloning site of the vector. The $1.2 \mathrm{~kb} A a t \mathrm{I} / \mathrm{KpnI}$ fragment was ligated with a $3.8 \mathrm{~kb}$ AatI/KpnI fragment from the pPmr3 vector, which contains the $V$. carteri hsp70A-rbcS3 tandem promoter $(0.77 \mathrm{~kb})$ and the pBluescript vector backbone. The final plasmid, pHRLucP (Figure 3D), is $5.0 \mathrm{~kb}$ in size and contains $0.77 \mathrm{~kb}$ of upstream sequence containing the $V$. carteri $h s p 70 \mathrm{~A}-r b c \mathrm{~S} 3$ tandem promoter, the $0.57 \mathrm{~kb}$ coding region of the G. princeps gluc gene, the $3^{\prime}$-UTR of the C. reinhardtii PSAD gene $(0.56 \mathrm{~kb})$, and the pBluescript vector backbone.

\section{Preparation of plasmid DNA}

Plasmid DNA was purified using the Nucleospin ${ }^{\circledR}$ Plasmid Kit according to the manufacturer's instructions (Macherey-Nagel, Düren, Germany).

\section{Coating of microprojectiles}

Gold microprojectiles (0.6 $\mu \mathrm{m}$ in diameter, Bio-Rad, Hercules, CA) were coated with the required plasmids for biolistic transformation [17]. For the transformation, approximately $3 \mathrm{mg}$ of the gold microprojectiles in $50 \mu \mathrm{l}$ of $\mathrm{H}_{2} \mathrm{O}$ was quickly mixed with $5 \mu \mathrm{g}$ of the circular selectable marker plasmid DNA (concentration $>0.5 \mu \mathrm{g}$ / $\mu \mathrm{l}), 5 \mu \mathrm{g}$ of the circular co-bombarded plasmid (concentration $>0.5 \mu \mathrm{g} / \mu \mathrm{l}), 40 \mu \mathrm{l}$ of $\mathrm{CaCl}_{2}(2.5 \mathrm{M})$, and $20 \mu \mathrm{l}$ of spermidine (0.1 M, Sigma-Aldrich) [17]. Mixing was sustained for $30 \mathrm{~min}$ at $4^{\circ} \mathrm{C}$, after which $200 \mu \mathrm{l}$ of ethanol (at room temperature) was added and the suspension centrifuged for $2-3 \mathrm{~s}$ at $\sim 5,000 \mathrm{~g}$. The pellet was washed three times with $100 \mu \mathrm{l}$ of ethanol (at $-20^{\circ} \mathrm{C}$ ) and centrifuged for 2-3 s at $\sim 5,000 \mathrm{~g}$. Finally, the DNA-coated microprojectiles were resuspended in $60 \mu \mathrm{l}$ of ethanol and kept at $4^{\circ} \mathrm{C}$; these microprojectiles were used within $3 \mathrm{~h}$ of preparation.

\section{Determination of cell concentration}

In E. elegans, the number of cells per colony varies significantly not only among individuals cultured under different conditions but also among individuals cultured under the same conditions. Therefore, we report the concentration as cells $/ \mathrm{ml}$ rather than colonies $/ \mathrm{ml}$. The concentration of cells was determined using a hemacytometer with Neubauer ruling.

\section{Stable nuclear transformation by particle bombardment}

A logarithmically growing E. elegans culture $(150 \mathrm{ml})$ at a cell concentration of $\sim 6 \times 10^{4}$ cells $/ \mathrm{ml}$ was harvested by centrifugation ( $800 \mathrm{~g}, 5 \mathrm{~min}$, swing-out rotor) and resuspended in $6 \mathrm{ml}$ of VM. One milliliter of the suspension was evenly spread on a cellulose acetate membrane 
filter with a pore size of $1.2 \mu \mathrm{m}$ and a diameter $47 \mathrm{~mm}$ (Whatman, London, UK), and the filter was placed on top of a stack of absorbent paper to soak up the excess liquid [17]. The stable transformation of E. elegans was performed using a Biolistic ${ }^{\circledR}$ PDS-1000/He (Bio-Rad) particle gun. One-sixth of the DNA-coated microprojectiles were spread on a macrocarrier (Bio-Rad), which was placed in a macrocarrier holder (Bio-Rad). In the most successful combination of parameters (see Additional file 1), the distance between the macrocarrier and stopping screen (Bio-Rad) was adjusted to $7 \mathrm{~mm}$ and the Helium pressure was set to 1,100 psi (as defined by rupture disks with the corresponding burst pressure). Finally, the distance between rupture disk and macrocarrier was set to $8 \mathrm{~mm}$. The membrane filter with its layer of E. elegans cells was positioned in the bombardment chamber, and the distance between the target cells and the stopping screen was adjusted to $8 \mathrm{~cm}$. The chamber was partly evacuated to 27 inches of $\mathrm{Hg}$ [17]. After the bombardment step, the colonies were washed off of the membrane filter with VM. The procedure was repeated five times, and the algae from six rounds of bombardment were pooled and then evenly distributed among twelve $50 \mathrm{ml}$ Erlenmeyer flasks containing a volume of $\sim 40 \mathrm{ml}$ of VM. The bombarded algae were incubated under standard conditions for $24 \mathrm{~h}$, and then $2 \mu \mathrm{g}$ of paromomycin/ml was added. The large fraction of non-transformed cells died within $48 \mathrm{~h}$, which resulted in a clarification of the medium. After 9-12 days of incubation in the presence of antibiotic, re-greening of flasks indicated the initial presence and reproduction of at least one paromomycin-resistant E. elegans cell, which led to a population of transformants. No more than one transformant per flask was analyzed [17].

\section{Re-isolation of transformants}

Transformants were re-isolated for detailed analyses to ensure uniform genetic conditions [17]. For this purpose, a serial dilution of an exponentially growing $E$. elegans culture was performed in a Terasaki plate (Nunc $^{\mathrm{TM}}$ MicroWell $^{\mathrm{TM}}$ MiniTrays; Thermo Fisher Scientific, Langenselbold, Germany). Each well of the Terasaki plate was filled with $10 \mu \mathrm{l}$ of VM. A single E. elegans colony was finally transferred into a standard glass tube with $\mathrm{VM}$, containing $1 \mu \mathrm{g}$ of paromomycin $/ \mathrm{ml}$, and incubated under standard conditions.

\section{Paromomycin-resistance assay}

Transformed or wild-type E. elegans strains were transferred into the wells of a 24-well cell culture plate (Sarstedt, Nümbrecht, Germany) with a wide range of paromomycin concentrations from 0 to $100 \mu \mathrm{g} / \mathrm{ml}$ (concentrations are given in Figure 2A). At the beginning of the assay, each well contained approximately 1,600 cells, which corresponds to 50-70 colonies, in a total VM volume of $1 \mathrm{ml}$.
After incubation under standard conditions for 10 days, the wells were analyzed for viable green cells/colonies or lysed cells/colonies (white).

\section{Primer design}

Oligonucleotide primers were designed using Oligo 6 (Molecular Biology Insights, Cascade, CO), Primer Express $^{\circledR}$ (Applied Biosystems, Foster City, CA), and DNASIS $^{\mathrm{TM}}$ (version 7.00; Hitachi Software Engineering, San Francisco, CA).

\section{Isolation of genomic DNA}

Thirty-five milliliters of a logarithmically growing E. elegans culture (cell density of $2 \times 10^{6}$ cells $/ \mathrm{ml}$ ) was harvested by centrifugation $(3,500 \mathrm{~g}$ for $10 \mathrm{~min})$. The resulting pellet had a wet weight of $\sim 80 \mathrm{mg}$. Isolation of genomic DNA was performed using the DNeasy ${ }^{\circledR}$ Plant Mini Kit (Qiagen, Hilden, Germany). Larger amounts of genomic DNA were prepared by conventional methods [93], using tris-saturated phenol (Roti ${ }^{\circledR}$-phenol, Roth, Karlsruhe, Germany).

\section{Genomic PCR}

PCR utilizing genomic DNA as a template was conducted in a total volume of $50 \mu \mathrm{l}$, which contained approximately $100 \mathrm{ng}$ of genomic DNA, $300 \mathrm{nM}$ of each primer, $0.2 \mathrm{mM}$ dNTPs, $1.5 \mathrm{mM} \mathrm{MgCl}_{2}$, and 2.6 units of the Expand High Fidelity enzyme mix in 1x Expand High Fidelity buffer (Expand High Fidelity Plus PCR System, Roche Applied Science, Basel, Switzerland). The PCR reactions were performed on a T3 Thermocycler PCR system (Biometra, Göttingen, Germany) using the following conditions: 40 cycles of $94^{\circ} \mathrm{C}$ for $20 \mathrm{~s}, 55^{\circ} \mathrm{C}$ for $30 \mathrm{~s}$, and $72^{\circ} \mathrm{C}$ for $45 \mathrm{~s}$, followed by a final extension at $72^{\circ} \mathrm{C}$ for $10 \mathrm{~min}$. The PCR products were cloned and sequenced.

\section{Southern blotting}

Genomic DNA was fragmented by restriction enzyme digestion, and the fragments were separated on $1 \%$ agarose gels, vacuum transferred to nylon membranes (Hybond- $\mathrm{N}^{\circledR}$; Amersham Biosciences, Little Chalfont, UK), and fixed to the membrane by baking at $120^{\circ} \mathrm{C}$ for 30 min using standard protocols [93]. Fragments of the S. rimosus aphVIII (282 bp; Figure 3A) or the codonoptimized G. princeps gluc (258 bp; Figure 3D) coding regions were amplified by PCR (Expand High Fidelity Plus PCR System; Roche Applied Science) and simultaneously labeled using a digoxigenin DNA labeling mix (PCR DIG labeling mix; Roche Applied Science). Prehybridization at $52^{\circ} \mathrm{C}$, hybridization at $52^{\circ} \mathrm{C}$, and washing steps were conducted in standard solutions (Roche Applied Science). Hybridizing bands were detected using an anti-digoxigenin-alkaline phosphatase conjugate (1:7500 
dilution) and the chemiluminescent substrate CDP Star ${ }^{\circledR}$ following the manufacturer's instructions for the chemiluminescence reagent (Roche Applied Science). The treated membranes were exposed to light-sensitive film (Retina XBA; Fotochemische Werke, Berlin, Germany) for 2-15 $\min$.

\section{Isolation of total RNA}

Total RNA was extracted from $100 \mathrm{mg}$ (wet weight) of concentrated, frozen algae using $1 \mathrm{ml}$ of the phenolbased TRI Reagent (Sigma-Aldrich, St. Louis, MO) and $300 \mu \mathrm{l}$ trichloromethane. RNA quantitation and purity checks were conducted by agarose-formaldehyde gel electrophoresis and by measuring absorption at 260 and $280 \mathrm{~nm}$ with an Ultrospec 2100 pro UV/Visible Spectrophotometer (GE Healthcare, Uppsala, Sweden).

\section{Reverse Transcription (RT)-PCR}

Reverse transcription was performed using $1 \mu \mathrm{g}$ of total RNA and Moloney murine leukemia virus (MMLV) reverse transcriptase lacking ribonuclease $H$ activity $(H$ minus) according to the instructions of the manufacturer (Promega). The subsequent PCR was carried out using the Expand High Fidelity PCR system (Roche Applied Science), a T3 Thermocycler PCR system (Biometra), and the following cycling conditions: 40 cycles of $94^{\circ} \mathrm{C}$ for $20 \mathrm{~s}, 55^{\circ} \mathrm{C}$ for $30 \mathrm{~s}$, and $72^{\circ} \mathrm{C}$ for $45 \mathrm{~s}$, followed by a final extension step at $72^{\circ} \mathrm{C}$ for $10 \mathrm{~min}$. The RT-PCR products were cloned and sequenced.

\section{Optimum temperature for heat stress-induced expression of luciferase}

Cultures of E. elegans transformants that express the gluc gene following the genomic integration of the cotransformed plasmids pHRLucP or pHsp70A-GLuc were grown logarithmically at $27^{\circ} \mathrm{C}$ and divided into aliquots of $10 \mathrm{ml}$. The aliquots were incubated for $1 \mathrm{~h}$ at temperatures ranging from $27^{\circ} \mathrm{C}$ to $57^{\circ} \mathrm{C}\left(3^{\circ} \mathrm{C}\right.$ intervals). After a recovery phase at $27^{\circ} \mathrm{C}$ for $15 \mathrm{~min}$, the algae were harvested by centrifugation $(3,500 \mathrm{~g}$ for $5 \mathrm{~min})$, resuspended in $300 \mu \mathrm{l}$ of assay buffer $(0.1 \mathrm{M}$ potassium phosphate ( $\mathrm{pH} 7.6), 0.5 \mathrm{M} \mathrm{NaCl}, 1 \mathrm{mM}$ EDTA), and disrupted by sonification using a Sonopuls ${ }^{\mathrm{TM}}$ HD2070 sonicator (Bandelin Electronic, Berlin, Germany). Luciferase activity was measured at $20^{\circ} \mathrm{C}$ as described previously [82] using a MiniLumat LB9506 luminometer (Berthold, Bad Wildbad, Germany). The luminescence was recorded in relative light units.

\section{Luciferase assay}

For assays on light-sensitive films and for photo-optical documentation of luciferase activity, Eudorina cultures $\left(3-6 \times 10^{6}\right.$ cells $\left./ \mathrm{ml}\right)$ were divided into aliquots of $50 \mathrm{ml}$. One aliquot was incubated at the optimal temperature for heat stress-induced expression of luciferase $\left(42^{\circ} \mathrm{C}\right)$ for $1 \mathrm{~h}$, and another aliquot was incubated at $27^{\circ} \mathrm{C}$ as a reference control. Subsequently, the cultures were centrifuged (3,500 g for $5 \mathrm{~min}$ ), resuspended in $850 \mu \mathrm{l}$ of assay buffer, and disrupted by two $30 \mathrm{~s}$ pulses of direct sonication using a Sonopuls ${ }^{\mathrm{TM}}$ HD2070 sonicator (Bandelin Electronic) at $70 \%$ power. Lysates were then transferred into individual wells of a 24-well cell culture plate (Sarstedt). After addition of $150 \mu \mathrm{l}$ of $0.05 \mathrm{mM}$ coelenterazine (Fluka, Neu-Ulm, Germany) in assay buffer, the 24-well plate was exposed to a chemiluminescencesensitive film (Retina XBA; Fotochemische Werke, Berlin, Germany) for $2 \mathrm{~h}$ at $20^{\circ} \mathrm{C}$ [94]. In addition, the luciferase activity of transformant lysates in 24-well cell culture plates was documented photo-optically using a Canon Eos 20D photo camera (Canon, Tokio, Japan) with exposure times of 2 to $30 \mathrm{~min}$. Quantification of luciferase activity was conducted as described previously [82] using a MiniLumat LB9506 luminometer (Berthold).

\section{In-gel activity assay}

Logarithmically growing, heat-stressed cultures of E. elegans transformants expressing the gluc gene were centrifuged (4,000 $\mathrm{g}$ for $5 \mathrm{~min})$, resuspended in $20 \mathrm{mM}$ sodium phosphate buffer $\mathrm{pH}$ 7.6, and disrupted using a Sonopuls ${ }^{\text {TM }}$ HD2070 sonicator (Bandelin Electronic). The lysate was cleared by centrifugation $(80,000 \mathrm{~g}$ for 45 min) at $4^{\circ} \mathrm{C}$, and the protein concentration of the cell extract was determined using the Bio-Rad Protein Assay Dye Reagent (Bio-Rad). Cell extracts containing $20 \mu \mathrm{g}$ of total protein in a volume of $15 \mu \mathrm{l}$ were mixed with $15 \mu \mathrm{l}$ of gel loading buffer without thiol reagents, incubated at $23^{\circ} \mathrm{C}$ for 5 minutes, centrifuged (16,000 g for $2 \mathrm{~min}$ ), and loaded (without heating) onto a SDS-polyacrylamide gel (15\% separation gel, 5\% stacking gel). After electrophoresis at $20 \mathrm{~mA}$ for $1.5 \mathrm{~h}$ (at $4^{\circ} \mathrm{C}$ ), the gel was rinsed in ultrapure water (Milli-Q, Millipore, Bedford, MA) for $20 \mathrm{~s}$. For in-gel renaturation of luciferase, the gel was incubated twice in renaturation buffer $(20 \mathrm{mM}$ sodium phosphate buffer ( $\mathrm{pH}$ 7.6), 0.5\% $\beta$-cyclodextrin) with gentle shaking for $15 \mathrm{~min}$ each. The cyclic oligosaccharide $\beta$-cyclodextrin supports protein refolding following SDS-polyacrylamide gel electrophoresis because it is able to capture SDS [86]. After the renaturation step, the gel was incubated in assay buffer for $15 \mathrm{~min}$ with gentle shaking and then transferred to a glass-fiber filter paper with a pore size of $0.45 \mu \mathrm{m}$ (Macherey-Nagel), which was soaked in assay buffer with $0.05 \mathrm{mM}$ coelenterazine substrate. Then, the gel on the filter paper was covered with a thin transparent plastic wrap (SC Johnson, Racine, WI); a light-sensitive film (Retina XBA; Fotochemische Werke, Berlin, Germany) was placed on top, and slight pressure was applied evenly to the sandwich by a flat weight of 150 g. The gel was exposed to the light-sensitive film for $12 \mathrm{~h}$. 


\section{Additional files}

\section{Additional file 1: Summary of the optimal combination of the parameters for E. elegans transformation. \\ Additional file 2: Paromomycin resistance in transformants. Additional file 3: Luciferase activity of transformants at increased temperatures.}

\section{Abbreviations}

aphVIII: S. rimosus aminoglycoside 3'-phosphotransferase VIII gene; GFP: Green fluorescent protein; gluc: G. princeps luciferase gene; hsp70A: Heat shock protein 70A gene; MMLV: Moloney murine leukemia virus; PCR: Polymerase chain reaction; PSAD: Abundant protein of photosystem complex gene; rbcS3: Ribulose bisphosphate carboxylase small chain gene 3; rlu: Relative light units; RT: Reverse transcription; SDS: Sodium dodecyl sulfate; UTR: Untranslated region; VM: Volvox medium.

\section{Competing interests}

The authors declare that they have no competing interests.

\section{Authors' contributions}

$\mathrm{KL}$ conducted the experiments, analyzed the data, and wrote the first version of the manuscript with advice and guidance from $\mathrm{AH}$. $\mathrm{AH}$ (corresponding author) conceived and coordinated the study, critically evaluated the data, and finalized the manuscript. Both authors read and approved the final manuscript.

\section{Acknowledgements}

We are grateful to T. Jakobiak and R. Schmitt (University of Regensburg, Germany) for providing the aphVIII gene, to N. Shao and R. Bock (MaxPlanck-Institut für Molekulare Pflanzenphysiologie, Potsdam-Golm, Germany) for providing the gluc gene, and to K. Puls for technical assistance. We acknowledge the support of the Deutsche Forschungsgemeinschaft and the Open Access Publication Funds of Bielefeld University, which funded the article processing charges.

Received: 24 September 2012 Accepted: 8 February 2013 Published: 12 February 2013

\section{References}

1. Baldauf SL: The deep roots of eukaryotes. Science 2003, 300(5626):1703-1706.

2. King N: The unicellular ancestry of animal development. Dev Cell 2004, 7(3):313-325.

3. Grosberg RK, Strathmann R: The evolution of multicellularity: a minor major transition? Annu Rev Ecol Evol Syst 2007, 38:621-654.

4. Prochnik SE, Umen J, Nedelcu AM, Hallmann A, Miller SM, Nishii I, Ferris P, Kuo A, Mitros T, Fritz-Laylin LK, et al: Genomic analysis of organismal complexity in the multicellular green alga Volvox carteri. Science 2010, 329(5988):223-226.

5. Kirk DL: Volvox: molecular-genetic origins of multicellularity and cellular differentiation. 1st edition. Cambridge: Cambridge University Press; 1998.

6. Kirk DL: A twelve-step program for evolving multicellularity and a division of labor. BioEssays 2005, 27(3):299-310.

7. Hallmann A: Evolution of reproductive development in the volvocine algae. Sex Plant Reprod 2011, 24:97-112.

8. Marchant $\mathrm{HJ}$ : Colony formation and inversion in the green alga Eudorina elegans. Protoplasma 1977, 93:325-339.

9. Merchant SS, Prochnik SE, Vallon O, Harris EH, Karpowicz SJ, Witman GB, Terry A, Salamov A, Fritz-Laylin LK, Marechal-Drouard L, et al: The Chlamydomonas genome reveals the evolution of key animal and plant functions. Science 2007, 318(5848):245-250.

10. Harris EH, Stern DB, Witman GB: The Chlamydomonas Sourcebook. 2nd edition. San Diego, CA: Academic Press; 2009.

11. Stein JR: A morphologic and genetic study of Gonium pectorale. Am J Bot 1958, 45(9):664-672.

12. Stein JR: Sexual populations of Gonium pectorale (Volvocales). Am J Bot 1965, 52(4):379-388.
13. Hamaji T, Nishii I, Nozaki H: Genomic analysis on mating type loci in the colonial volvocalean algae Gonium pectorale and Pleodorina starrii. Phycologia 2009, 48(4):38-38.

14. Hamaji T, Ferris PJ, Coleman AW, Waffenschmidt S, Takahashi F, Nishii I, Nozaki H: Identification of the minus-dominance gene ortholog in the mating-type locus of Gonium pectorale. Genetics 2008, 178(1):283-294.

15. Greuel BT, Floyd GL: Development of the flagellar apparatus and flagellar orientation in the colonial green alga Gonium pectorale (Volvocales). J Phycol 1985, 21:358-371.

16. Fabry S, Köhler A, Coleman AW: Intraspecies analysis: comparison of ITS sequence data and gene intron sequence data with breeding data for a worldwide collection of Gonium pectorale. J Mol Evol 1999, 48(1):94-101.

17. Lerche K, Hallmann A: Stable nuclear transformation of Gonium pectorale. BMC Biotechnol 2009, 9(1):64.

18. Schagerl M, Angeler D, Coleman A: Infraspecific phylogeny of Pandorina morum (Volvocales, Chlorophyta) inferred from molecular, biochemical and traditional data. Eur J Phycol 1999, 34:87-93.

19. Coleman AW, Maguire MJ: A simplified, rapid method for identifying mating type in algae: results with the Pandorina morum species complex. J Phycol 1983, 19:536-539.

20. Nozaki H: The asexual reproduction of Japanese Pandorina morum Bory (Chlorophyta, Volvocales). Jap J Phycol 1980, 28(3):157-158.

21. Nozaki H, Kazaki H: The sexual process of Japanese Pandorina morum Bory (Chlorophyta). J Jpn Bot 1979, 54(12):363-370.

22. Fulton $A B$ : Colonial development in Pandorina morum. I. Structure and composition of the extracellular matrix. Dev Biol 1978, 64(2):224-235.

23. Coleman AW: Sexual and genetic isolation in the cosmopolitan algal species Pandorina morum. Am J Bot 1977, 64(3):361-368.

24. Goldstein M: Speciation and mating behaviour in Eudorina. J Protozool 1964, 11(3):317-344.

25. Goldstein M: Colony differentiation in Eudorina. Can J Bot 1967, 45:1591-1596.

26. Mishra NC, Threlkeld SF: Genetic studies in Eudorina. Genet Res 1968, 11(1):21-31.

27. Kemp CL, Wentworth JW: Ultraviolet radiation studies on the colonial alga, Eudorina elegans. Can J Microbiol 1971, 17(11):1417-1424.

28. Toby $\mathrm{AL}$, Kemp CL: Mutant enrichment in the colonial alga, Eudorina elegans. Genetics 1975, 81(2):243-251.

29. Gottlieb B, Goldstein ME: Colony development in Eudorina elegans (Chlorophyta, Volvocales). J Phycol 1977, 13(4):358-364.

30. Toby AL, Kemp CL: Nitrate reductase mutants in Eudorina elegans (Chlorophyceae). J Phycol 1977, 13(4):368-372.

31. Toby AL, Kemp CL: A preliminary-study of nitrogen-metabolism in Eudorina elegans. Can J Genet Cytol 1980, 22(4):681.

32. Kemp CL: Genetic studies of Eudorina elegans (Chlorophyceae). Can J Genet Cytol 1981, 23(3):425-432

33. Kemp $\mathrm{CL}$, Toby $\mathrm{AL}$ : Examination of in vivo nitrate reductase regulation in Eudorina elegans. Can J Genet Cytol 1982, 24(5):627-628.

34. Nozaki H: Sexual reproduction in Eudorina elegans (Chlorophyta, Volvocales). Bot Mag (Tokyo) 1983, 96:103-110.

35. Nozaki H: Zygote germination in Eudorina elegans var. synoica (Chlorophyta, Volvocales). J Jpn Bot 1986, 61(10):316-320.

36. Hoops HJ, Long JJ, Hile ES: Flagellar apparatus structure is similar but not identical in Volvulina steinii, Eudorina elegans, and Pleodorina illinoisensis (Chlorophyta) - implications for the volvocine evolutionary lineage. J Phycol 1994, 30(4):679-689.

37. Shaw WR: Pleodorina, a new genus of the Volvocinae. Bot Gaz 1894 19:279-283.

38. Kikuchi K: Cellular differentiation in Pleodorina californica. Cytologia (Tokyo) 1978, 43:153-160.

39. Nozaki H, Kuroiwa T: Ultrastructure of the extracellular matrix and taxonomy of Eudorina, Pleodorina and Yamagishiella gen. nov. (Volvocaceae, Chlorophyta). Phycologia 1992, 31(6):529-541.

40. Coleman AW: Comparison of Eudorina / Pleodorina ITS sequences of isolates from nature with those from experimental hybrids. Am J Bot 2002, 89(9):1523-1530.

41. Nozaki $\mathrm{H}$ : Origin and evolution of the genera Pleodorina and Volvox (Volvocales). Biologia (Bratisl) 2003, 58(4):425-431.

42. Nozaki H, Ott FD, Coleman AW: Morphology, molecular phylogeny and taxonomy of two new species of Pleodorina (Volvoceae, Chlorophyceae). J Phycol 2006, 42(5):1072-1080. 
43. Nozaki H: A new male-specific gene "OTOKOGI" in Pleodorina starrii (Volvocaceae, Chlorophyta) unveils the origin of male and female. Biologia (Bratisl) 2008, 63(8):772-777.

44. Schiedlmeier B, Schmitt R, Müller W, Kirk MM, Gruber H, Mages W, Kirk DL: Nuclear transformation of Volvox carteri. Proc Natl Acad Sci USA 1994 91(11):5080-5084.

45. Kindle KL, Schnell RA, Fernandez E, Lefebvre PA: Stable nuclear transformation of Chlamydomonas using the Chlamydomonas gene for nitrate reductase. J Cell Biol 1989, 109(6 Pt 1):2589-2601.

46. Kindle KL: High-frequency nuclear transformation of Chlamydomonas reinhardtii. Proc Natl Acad Sci USA 1990, 87(3):1228-1232.

47. Brown LE, Sprecher SL, Keller LR: Introduction of exogenous DNA into Chlamydomonas reinhardtii by electroporation. Mol Cell Biol 1991, 11(4):2328-2332.

48. Nozaki H, Itoh M, Sano R, Uchida H, Watanabe MM, Kuroiwa T: Phylogenetic relationships within the colonial Volvocales (Chlorophyta) inferred from rbcL gene sequence data. J Phycol 1995, 31:970-979.

49. Mai JC, Coleman AW: The internal transcribed spacer 2 exhibits a common secondary structure in green algae and flowering plants. $J \mathrm{Mol}$ Evol 1997, 44(3):258-271.

50. Liss M, Kirk DL, Beyser K, Fabry S: Intron sequences provide a tool for high-resolution phylogenetic analysis of volvocine algae. Curr Genet 1997, 31(3):214-227.

51. Nozaki H, Ito M, Uchida H, Watanabe MM, Kuroiwa T: Phylogenetic analysis of Eudorina species (Volvocaceae, Chlorophyta) based on rbcL gene sequences. J Phycol 1997, 33(5):859-863.

52. Coleman AW: Phylogenetic analysis of "Volvocaceae" for comparative genetic studies. Proc Natl Acad Sci USA 1999, 96(24):13892-13897.

53. Nozaki H, Ohta N, Takano H, Watanabe MM: Reexamination of phylogenetic relationships within the colonial Volvocales (Chlorophyta) an analysis of atpB and rbcL gene sequences. J Phycol 1999, 35:104-112.

54. Nozaki H, Misawa K, Kajita T, Kato M, Nohara S, Watanabe MM: Origin and evolution of the colonial Volvocales (Chlorophyceae) as inferred from multiple, chloroplast gene sequences. Mol Phylogenet Evol 2000, 17(2):256-268.

55. Nozaki H, Krienitz L: Morphology and phylogeny of Eudorina minodii (Chodat) Nozaki et Krienitz, comb. nov (Volvocales, Chlorophyta) from Germany. Eur J Phycol 2001, 36(1):23-28.

56. Yamada TK, Miyaji K, Nozaki H: A taxonomic study of Eudorina unicocca (Volvocaceae, Chlorophyceae) and related species, based on morphology and molecular phylogeny. Eur J Phycol 2008, 43(3):317-326.

57. Yamada TK, Tsuchikane Y, Wu J-T, Sekimoto H, Miyaji K, Nozaki H: Morphology and molecular phylogeny of Eudorina sp. (Volvocaceae, Chlorophyceae) from Taiwan. Hikobia 2008, 15(2):135-143.

58. Nakada T, Shinkawa H, Ito T, Tomita M: Recharacterization of Chlamydomonas reinhardtii and its relatives with new isolates from Japan. J Plant Res 2010, 123(1):67-78.

59. Calmels T, Parriche M, Durand H, Tiraby G: High efficiency transformation of Tolypocladium geodes conidiospores to phleomycin resistance. Curr Genet 1991, 20(4):309-314.

60. Drocourt D, Calmels T, Reynes JP, Baron M, Tiraby G: Cassettes of the Streptoalloteichus hindustanus ble gene for transformation of lower and higher eukaryotes to phleomycin resistance. Nucleic Acids Res 1990, 18(13):4009.

61. Gatignol A, Durand H, Tiraby G: Bleomycin resistance conferred by a drugbinding protein. FEBS Lett 1988, 230(1-2):171-175.

62. Stevens DR, Rochaix JD, Purton S: The bacterial phleomycin resistance gene ble as a dominant selectable marker in Chlamydomonas. Mol Gen Genet 1996, 251(1):23-30.

63. Hallmann A, Rappel A: Genetic engineering of the multicellular green alga Volvox: a modified and multiplied bacterial antibiotic resistance gene as a dominant selectable marker. Plant J 1999, 17(1):99-109.

64. Danilenko VN, Akopiants KE, Sizova IA, Michurina TA: Determination of the nucleotide sequence and characterization of the novel aminoglycoside phosphotransferase aphVIII gene from the Streptomyces rimosus strain. Genetika 1997, 33(11):1478-1486.

65. Sizova I, Fuhrmann M, Hegemann P: A Streptomyces rimosus aphVIII gene coding for a new type phosphotransferase provides stable antibiotic resistance to Chlamydomonas reinhardtii. Gene 2001, 277(1-2):221-229.

66. Hallmann A, Wodniok S: Swapped green algal promoters: aphVIII-based gene constructs with Chlamydomonas flanking sequences work as dominant selectable markers in Volvox and vice versa. Plant Cell Rep 2006, 25(6):582-591.

67. Jakobiak T, Mages W, Scharf B, Babinger P, Stark K, Schmitt R: The bacterial paromomycin resistance gene, $a p h H$, as a dominant selectable marker in Volvox carteri. Protist 2004, 155(4):381-393.

68. Cerutti H, Johnson AM, Gillham NW, Boynton JE: A eubacterial gene conferring spectinomycin resistance on Chlamydomonas reinhardtii: integration into the nuclear genome and gene expression. Genetics 1997, 145(1):97-110

69. Berthold P, Schmitt R, Mages W: An engineered Streptomyces hygroscopicus aph 7" gene mediates dominant resistance against hygromycin B in Chlamydomonas reinhardtii. Protist 2002, 153(4):401-412.

70. Randolph-Anderson BL, Sato R, Johnson AM, Harris EH, Hauser CR, Oeda K, Ishige F, Nishio S, Gillham NW, Boynton JE: Isolation and characterization of a mutant protoporphyrinogen oxidase gene from Chlamydomonas reinhardtii conferring resistance to porphyric herbicides. Plant Mol Biol 1998, 38(5):839-859.

71. Kovar JL, Zhang J, Funke RP, Weeks DP: Molecular analysis of the acetolactate synthase gene of Chlamydomonas reinhardtii and development of a genetically engineered gene as a dominant selectable marker for genetic transformation. Plant J 2002, 29(1):109-117.

72. Nelson JA, Savereide PB, Lefebvre PA: The CRY1 gene in Chlamydomonas reinhardtii: structure and use as a dominant selectable marker for nuclear transformation. Mol Cell Biol 1994, 14(6):4011-4019.

73. Fischer N, Rochaix JD: The flanking regions of PsaD drive efficient gene expression in the nucleus of the green alga Chlamydomonas reinhardtii. Mol Genet Genomics 2001, 265(5):888-894.

74. Schroda M, Blöcker D, Beck CF: The HSP70A promoter as a tool for the improved expression of transgenes in Chlamydomonas. Plant J 2000, 21(2):121-131.

75. Hallmann A, Sumper M: The Chlorella hexose/ $\mathrm{H}^{+}$symporter is a useful selectable marker and biochemical reagent when expressed in Volvox. Proc Natl Acad Sci USA 1996, 93(2):669-673.

76. Hallmann A, Sumper M: An inducible arylsulfatase of Volvox carteri with properties suitable for a reporter-gene system. Purification, characterization and molecular cloning. Eur J Biochem 1994, 221(1):143-150.

77. Hallmann A, Sumper M: Reporter genes and highly regulated promoters as tools for transformation experiments in Volvox carteri. Proc Natl Acad Sci USA 1994, 91(24):11562-11566.

78. Franklin S, Ngo B, Efuet E, Mayfield SP: Development of a GFP reporter gene for Chlamydomonas reinhardtii chloroplast. Plant J 2002, 30(6):733-744.

79. Matthews JC, Hori K, Cormier MJ: Purification and properties of Renilla reniformis luciferase. Biochemistry 1977, 16(1):85-91.

80. Fuhrmann M, Hausherr A, Ferbitz L, Schödl T, Heitzer M, Hegemann P. Monitoring dynamic expression of nuclear genes in Chlamydomonas reinhardtii by using a synthetic luciferase reporter gene. Plant Mol Biol 2004, 55(6):869-881.

81. Verhaegent M, Christopoulos TK: Recombinant Gaussia luciferase. Overexpression, purification, and analytical application of a bioluminescent reporter for DNA hybridization. Anal Chem 2002, 74(17):4378-4385.

82. Shao N, Bock R: A codon-optimized luciferase from Gaussia princeps facilitates the in vivo monitoring of gene expression in the model alga Chlamydomonas reinhardtii. Curr Genet 2008, 53(6):381-388.

83. Hallmann A, Rappel A, Sumper M: Gene replacement by homologous recombination in the multicellular green alga Volvox carteri. Proc Natl Acad Sci USA 1997, 94(14):7469-7474.

84. Drzymalla C, Schroda M, Beck CF: Light-inducible gene HSP70B encodes a chloroplast-localized heat shock protein in Chlamydomonas reinhardtii. Plant Mol Biol 1996, 31(6):1185-1194.

85. Laemmli UK: Cleavage of structural proteins during the assembly of the head of bacteriophage T4. Nature 1970, 227(259):680-685.

86. Yamamoto E, Yamaguchi S, Nagamune T: Effect of beta-cyclodextrin on the renaturation of enzymes after sodium dodecyl sulfatepolyacrylamide gel electrophoresis. Anal Biochem 2008, 381(2):273-275.

87. Sizova IA, Lapina TV, Frolova ON, Alexandrova NN, Akopiants KE, Danilenko VN Stable nuclear transformation of Chlamydomonas reinhardtii with a Streptomyces rimosus gene as the selective marker. Gene 1996, 181(1-2):13-18.

88. Diener DR, Curry AM, Johnson KA, Williams BD, Lefebvre PA, Kindle KL, Rosenbaum JL: Rescue of a paralyzed-flagella mutant of Chlamydomonas by transformation. Proc Natl Acad Sci USA 1990, 87(15):5739-5743. 
89. Dent RM, Haglund CM, Chin BL, Kobayashi MC, Niyogi KK: Functional genomics of eukaryotic photosynthesis using insertional mutagenesis of Chlamydomonas reinhardtii. Plant Physiol 2005, 137(2):545-556.

90. Tang DK, Qiao SY, Wu M: Insertion mutagenesis of Chlamydomonas reinhardtii by electroporation and heterologous DNA. Biochem Mol Biol Int 1995, 36(5):1025-1035.

91. Liu YG, Mitsukawa N, Oosumi T, Whittier RF: Efficient isolation and mapping of Arabidopsis thaliana T-DNA insert junctions by thermal asymmetric interlaced PCR. Plant J 1995, 8(3):457-463.

92. Provasoli L, Pintner IJ: Artificial media for fresh-water algae: problems and suggestions. In The Ecology of Algae, a symposium held at the Pymatuning Laboratory of Field Biology on June 18 and 19, 1959. 1st edition. Edited by Tryon CA, Hartman RT. Pittsburgh, PA: The Pymatuning Symposia in Ecology, Special Publication No. 2, University of Pittsburgh; 1959:84-96.

93. Sambrook J, Russell DW: Molecular Cloning: A Laboratory Manual, vol. 1-3. 3rd edition. Cold Spring Harbor, NY: Cold Spring Harbor Laboratory Press; 2001.

94. Jacobsen I, Hennig-Pauka I, Baltes N, Trost M, Gerlach GF: Enzymes involved in anaerobic respiration appear to play a role in Actinobacillus pleuropneumoniae virulence. Infect Immun 2005, 73(1):226-234.

doi:10.1186/1472-6750-13-11

Cite this article as: Lerche and Hallmann: Stable nuclear transformation of Eudorina elegans. BMC Biotechnology 2013 13:11.

\section{Submit your next manuscript to BioMed Central and take full advantage of:}

- Convenient online submission

- Thorough peer review

- No space constraints or color figure charges

- Immediate publication on acceptance

- Inclusion in PubMed, CAS, Scopus and Google Scholar

- Research which is freely available for redistribution 